\title{
Integration of biowaste into chemical reaction networks
}

Adarsh Arun, $^{a, c}$ Jana M. Weber, ${ }^{a, b}$ Zhen Guo ${ }^{b, c}$ and Alexei A. Lapkin ${ }^{a, b, c^{*}}$

${ }^{a}$ Department of Chemical Engineering and Biotechnology, University of Cambridge, Philippa Fawcett Drive, Cambridge CB3 OAS, UK

${ }^{b}$ Chemical Data Intelligence (CDI) Pte Ltd, Robinson Road, \#02-00, 068898 Singapore

${ }^{c}$ Cambridge Centre for Advanced Research and Education in Singapore, CARES Ltd. 1 CREATE Way, CREATE Tower \#05-05, 138602 Singapore

\section{Abstract}

As the chemical sector looks to decarbonize, one promising solution is the utilization of biofeedstocks and biowaste to produce functional molecules. There is, therefore, great interest in understanding how and where to integrate these resources within chemical supply chains. To assist such efforts, screening methodologies relying on large reaction networks have recently been proposed. ${ }^{1,2}$ However, they are currently hindered by a lack of data for regionspecific heterogenous raw materials compositions, as well as upstream pretreatments to isolate the important feedstocks. This study illustrates the workflow and data requirements of early stage biowaste stream evaluation through a case study on the waste landscape in and around the Singapore region. We first investigate biowaste sources that are available, stable in quantities, underutilized, pure, and yielding the feedstocks of interest. Oil palm empty fruit bunch (EFB), a lignocellulosic biowaste stream widely available in Malaysia and Indonesia, meets these criteria. We then simulate an ethanol organosolv pretreatment process for the fractionation of cellulose, lignin and xylose from EFB, and characterise the economic and 
environmental performances of the process through its exergy profile; this enables a link to chemical pathway identification in reaction networks. This study outlines the initial steps towards generating open datasets on biowaste for development of sustainable supply chains.

Keywords: circular economy; biomass pre-treatment; organosolv process; exergy analysis

\section{Introduction}

The concept of a circular chemical industry is a key aspect of future sustainable societies. Within this context, utilising biowaste as a feedstock is particularly promising as: $(i)$ the carbon loop can be closed through the biomass $c y c l e,{ }^{3}$ (ii) biowaste is often composed of complex molecules containing oxygen and nitrogen-based functional groups, ${ }^{4,5}$ and (iii) a reduction of the 1.3 billion tons of biowaste per year, which are globally estimated at present, is urgently needed..$^{6,7}$

The utilisation of biowaste for chemical production takes place either in the single stream specialised facilities, or in biorefineries. ${ }^{8-11}$ Biorefineries can potentially handle crude biowaste streams ranging from food waste to lignocellulosic waste that come from a variety of sectors, such as agricultural, industrial, forestry, and municipal.

The raw streams are complex and diverse in composition, but usually are a mixture of one or more of the following feedstocks ${ }^{5}$ : (i) biopolymers such as cellulose, hemicellulose, starch, chitin etc., (ii) mono or disaccharides such as glucose, sucrose, fructose, xylose, (iii) proteins, and (iv) extracts or secondary metabolites, such as triglycerides, terpenes, phenolics, tannins, carotenoids, sterols and flavonoids. Pretreatment technologies are required to fractionate the raw biowaste streams into these feedstocks, and further transformations can convert 
these feedstocks into value added platform chemicals ${ }^{1,4}$ for integration in chemical supply chains (details of this classification and specifics of the case study are given in Supporting Information, Figure S1). Thus, there exists a complex network of options, when varied composition raw materials could be pretreated using different processing technologies and these would yield a variation of feedstocks streams. In the end, this mix of processing steps and technologies must remain economically and environmentally competitive. ${ }^{10}$

To enumerate the economic and the environmental performance and to identify most suitable target chemicals, a systematic evaluation of reaction pathway options is needed at an early stage of new process development. The evaluation is commonly based on a reaction network, ${ }^{12}$ which may represent quite a significant part of chemical space.

Different small-scale case studies have been conducted in literature, relying on networks originating from a feedstock or a platform chemical. ${ }^{12-14}$ For instance, the pathway evaluation for renewables by Bao et al. starts with cellulose (feedstock), ${ }^{13}$ Voll and Marquardt focus on itaconic acid (platform chemical) ${ }^{12}$ and Jacob et al. on limonene (feedstock). ${ }^{14}$ However, these approaches do not yet account for the isolation of feedstocks from the biowaste streams in the first place, although for complete life cycle assessment of new technologies this is essential. Therefore, there is a need to expand reaction networks to include data on: (i) crude biowaste streams from which feedstocks can be obtained, and (ii) pretreatment methods to achieve this conversion.

In the context of gathering crude biowaste stream data, regional dependencies of biowaste sources hinders a one-size-fits-all solution, and requires in-depth local studies of availabilities and chemical compositions that reflect obtainable feedstocks. ${ }^{6,8}$ Geographical Information Systems have been utilised to locate agricultural biowaste resources, e.g. locations of palm 
oil or sugarcane mills as well as plantations, ${ }^{15,16}$ and domestic waste has been studied, for instance by sampling selected households. ${ }^{17}$ Alternatively, data provided by governmental agencies and literature can be used to gain a rough overview on the waste ecosystem and waste stream compositions at specific locations. In cases where quantitative data is not available the same sources could also be used to judge the practical viability of utilizing biowaste streams based on qualitative criteria.

Once a set of regionally available biowaste streams is identified and characterized, a similar analysis should be performed for pretreatment processes that can isolate feedstocks. There are a variety of pretreatment methods identified in literature, ${ }^{18,19}$ which differ with regards to the required raw materials, biowaste source, process conditions, processing steps, yields and recoveries of high-quality feedstocks. With this data, exergy analysis is a common method to characterize processes, as it links both to economic and environmental considerations, taking into account thermodynamic inefficiencies and losses. ${ }^{20-22}$ Furthermore, it can connect the pretreatment analysis to the subsequent reaction network analysis, where exergy has previously been applied as selection criteria. ${ }^{14,23}$ To evaluate the exergy requirement of biowaste pretreatment, previous literature has simulated processes in ASPEN Plus to extract enthalpy and entropy information and then compute exergetic profiles. ${ }^{24-28}$ For early-stage and large-scale evaluation of different treatments an automation of process modelling or heuristics for exergy profile estimations should be envisioned.

With identification and characterization of both biowaste streams and pretreatment processes for a given region, a pretreatment network can be assembled. A general example of such a network integrated with a conventional reaction network is shown in Figure 1. 
(i) Pre-treatment network

(ii) Reaction network

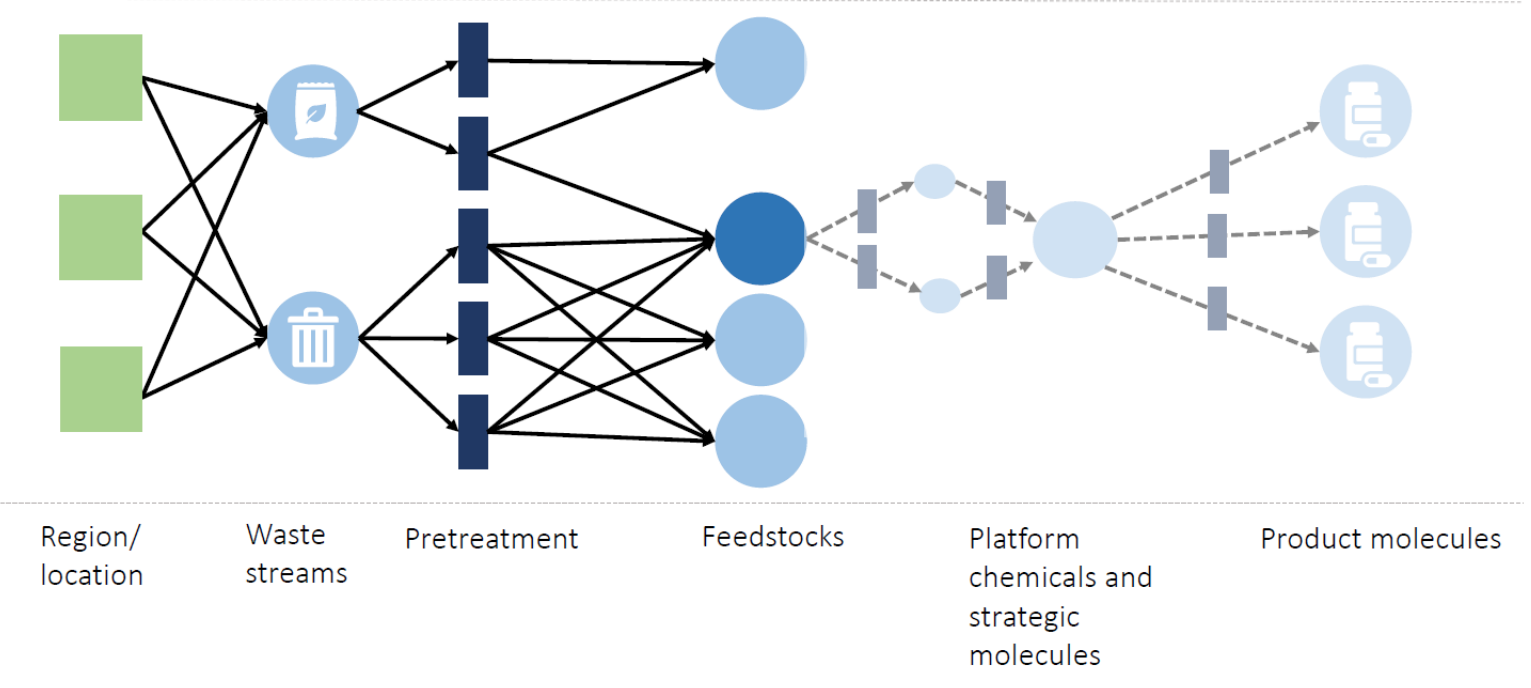

Figure 1. An illustration of network integration of a regional pre-treatment network (i) into a reaction network (ii). A multipartite network representation is selected outlining regions/locations as square nodes, materials and molecules as circular nodes and treatment and reactions as bar nodes. Multiple waste streams can connect via a variety of pre-treatment methods to feedstocks, as illustrated by the pretreatment network, part (i) of Figure 1. Feedstocks are the starting points in current chemical reaction networks, through a variety of options they can connect to high-value product molecules, as illustrated by the Reaction network, part (ii) of Figure 1.

Realizing such a network will require large-scale extraction and parsing of data from a variety of different sources that may or may not have the desired information. It is, therefore, prudent as a first step to conduct a case study of a chosen region to better understand data requirements and viability. For this study, the region of Singapore has been chosen, including its neighbours Malaysia and Indonesia. The primary aims are, to: 
a) Identify and characterize key biowaste streams/sources in the region. This will ideally involve quantified availabilities, qualitative judgements based on other criteria, and quantified chemical compositions, if data is available.

b) Select the most attractive biowaste stream based on its characterization data for further pretreatment.

c) Identify and simulate a pretreatment process for isolating feedstocks from the biowaste stream in Aspen PLUS. For this aim availability of data such as raw materials, process conditions, processing steps, feedstock recoveries and purities is crucial.

d) Conduct an exergy analysis on the chosen pretreatment process, highlighting inefficiencies, areas of improvement and trends.

It is important to note that the goal of this work is to build a foundation for future development of a comprehensive biowaste pretreatment network and its integration with reaction networks. The workflows addressing aims (a) to (d) will need to be replicated (with modifications where needed) across a larger range of regions, biowaste streams and pretreatment methods. Regardless, we hope that this study will stimulate a discussion in the wider community on the identification of key biowaste-derived molecular building blocks and the data requirements for enumeration of environmental impacts of circular chemical routes.

The rest of the paper is organized as follows. Section 2 outlines the methodology for addressing aims (a) to (d), Section 3 outlines key results for all aims, discussing contributions, and Section 4 concludes the study, highlighting key takeaways and future work needed. 


\section{Methods}

\subsection{Biowaste identification, characterization and selection}

This section outlines the methodology for addressing aims (a) and (b). Identification of key biowaste sources in Singapore and its neighbours was based on data from governmental organizations such as the National Environment Agency (NEA) in Singapore, MPOB (Malaysian Palm Oil Board), and GAPKI (Indonesian Palm Oil Board); literature, open source consultancy project reports, and correspondences with senior engineers in NEA. A set of five criteria based on biowaste reviews ${ }^{19,29-32}$ have been proposed to characterize the identified biowaste streams (aim (a)), along with key questions to answer which are outlined in Table 1.

Table 1. Criteria for biowaste characterization and selection.

No. Criteria Key questions

What is the estimated annual availability of the

$1 \quad$ Availability biowaste source?

2 Supply stability How stable is the biowaste supply from year to year?

3 Underutilization

Is the biowaste source an integral part of any material supply chains? How is it currently utilized? How segregated or pure is the biowaste source? Is it a

$4 \quad$ Purity and extent of segregation mixed or a single waste material stream?

What feedstocks can be extracted from the biowaste source? What value-added platform chemicals can be

$5 \quad$ Relevant feedstocks produced from them? What is the chemical composition of the biowaste source? 
Based on the five criteria, the waste streams can be evaluated and assessed, to identify the most attractive source for further pretreatment, aim (b). In general, the selected waste stream is required to be available at large quantities (1) and with relatively stable supply from year to year (2). While upgrading a waste stream from use as an energy source to material recovery (upgrade within the waste hierarchy) is advisable, focusing on underutilized waste (3) facilitates economic viability by the law of diminishing returns. Additionally, it is essential that useful feedstocks, leading to value-added platform chemicals, are present (5). If the biowaste source is already segregated at source or pure (4), this will further simplify isolation of these feedstocks.

The reader is referred to Sections 3.1 and 3.2 for results covering the identification and characterization of key biowaste sources in and around Singapore using the five criteria, respectively. Section 3.3 presents a summary, at the end of which oil palm empty fruit bunch (EFB), a type of lignocellulosic biowaste abundant in Malaysia and Indonesia, was selected for further pretreatment.

\subsection{Pretreatment process identification}

Having selected EFB, a compatible pretreatment method needs to be identified in accordance with aim (c). There exists a variety of processes for waste treatment, as mentioned in the introduction. While physical treatment (e.g. milling, freezing, extrusion) is commonly used for size reduction, chemical treatment (e.g. with acids, alkaline, or by organosolv process), physico-chemical (e.g. steam explosion, ultrasonic, liquid hot water), biological treatment (e.g. enzymatic, fungal, bacterial), or combined methods can fractionate and extract diverse sets of molecules. ${ }^{18,19}$ The ideal pre-treatment process is cheap, energy-efficient, suitable for 
different material types/compositions, and aids recovery of all feedstocks of interest at high qualities. Comprehensive advantages and disadvantages for treatment of lignocellulosic materials are provided in ref. 18.

One promising process for isolation of feedstocks from lignocellulosic materials is the organosolv process. ${ }^{18}$ Its main benefits are the production of pure cellulose and high-quality lignin (less condensed) at relatively lower temperatures and pressures unlike other methods that destroy the native lignin structure. ${ }^{33,34}$ Furthermore, a recent LCA review ${ }^{35}$ has identified it as the most environmentally favourable pretreatment technology for woody biomass. It employs an organic solvent (with water), typically with addition of an acid catalyst, to disrupt the lignin-hemicellulose matrix, fractioning the biomass into cellulose, lignin, hemicellulose sugars such as xylose and small quantities of furfural degradation products. The choice of solvent is a key decision-variable for the organosolv process. Low-boiling point alcohols such as ethanol are easier to recover after fractionation, cheaper and non-toxic, but require higher pressures (to maintain liquid phase). High boiling point alcohols on the other hand are more difficult to recover but can operate at ambient pressures. Other solvents such as formic acid and acetic acid dissolve lignin better at the expense of corrosivity and acylation of cellulose. ${ }^{36-}$ 38

\subsection{Pretreatment process simulation}

Simulating the organosolv process in Aspen PLUS, as per aim (c), requires a finer understanding of process conditions, material requirements, performance, as well as processing steps. 
Solvent choice, temperature, pressure, solvent concentration, acid catalyst, acid concentration, residence time, and solid-liquid ratio are some of the important process parameters/conditions that affect feedstock recoveries, purities as well as material requirements. To define them, we turn to experimental studies in literature that have examined EFB sourced from Indonesia and Malaysia. ${ }^{37,39}$ For instance, Mondylaksita et al. ${ }^{37}$ recently examined the ethanol organosolv process for EFB biowaste sourced from Indonesia and determined optimal process parameters for cellulose and lignin recovery. However, degradation products were not quantified. These process parameters have been summarized below in Table 2. Feedstock recoveries, purities and other performance metrics specified by the study are summarized in Table 3 .

Table 2. Summary of key process parameters for an ethanol organosolv process with EFB.

\begin{tabular}{lc}
\hline Process parameter & Value \\
\hline Solvent type and concentration & Ethanol (50 \% v in water) \\
Catalyst and concentration & $\mathrm{H}_{2} \mathrm{SO}_{4}(0.07 \mathrm{wt} \%$ based on dry biomass) \\
Temperature $\left({ }^{\circ} \mathrm{C}\right)$ & 210 \\
Pressure $($ bar $)$ & $\approx 37-40$ \\
Residence time in digester $(\mathrm{min})$ & 90 \\
Solid-liquid ratio & $1: 10$
\end{tabular}

Table 3. Summary of process performance for an ethanol organosolv process with EFB. 
(delignification)

Recovery of components in lignin-rich fraction and purity

Recovery of components in cellulose-rich fraction and purity

Recovery of components in hemicellulose-rich fraction and purity
$>70 \%$ lignin purity, $65 \%$ recovery of lignin, $5 \%$ recovery of cellulose, $6.5 \%$ recovery of hemicellulose

$>70 \%$ cellulose purity, $80 \%$ recovery of cellulose, $10 \%$ recovery of lignin, $15.4 \%$ recovery of hemicellulose Purity TBC* $\approx 80 \%$ recovery of xylose

*Xylose purity was calculated based on mass balances of other components.

There are many other process parameters and unit operations reliant on processing steps defined in the following section.

\section{Process model and processing steps}

The ethanol organosolv process was simulated using ASPEN Plus. The Non-Random Two Liquid (NRTL) model was chosen to handle non-idealities and the Redlich-Kwong-Soave (RKS) equation of state (EoS) was applied to account for high operating pressures. EFB was specified as per its estimated chemical composition expressed in terms of feedstocks (cellulose, lignin, hemicellulose) specified in Table 7 in Section 3.3 in the results. The National Renewable Energy Laboratory (NREL) database and technical reports were utilised to obtain thermodynamic properties of these feedstock biopolymers. ${ }^{40,41}$ For lignin and cellulose it was assumed that the molecular formula is unchanged after dissolution. Hemicellulose is 
hydrolysed to xylose due to its thermochemical sensitivity. Furfural degradation products and oligomers of each biopolymer are also expected but are not integrated due to the lack of data. Ash was included as calcium oxide $(\mathrm{CaO})^{41}$ and extractives were jointly included as a soluble sugar, glucose, and appear in all product streams as impurities.

The main processing steps of an organosolv process have been examined and simulated in more detail in prior literature $27,33,34,42$ and patents. ${ }^{43-45}$ For example, Viell et al. ${ }^{27}$ present an in-depth study on the ethanol organosolv process for wood chips considering fractionation of all products, additional washing stages, solvent recovery, heat integration and furfural separation. Kautto et al. ${ }^{42}$ presented an even more detailed ASPEN Plus process simulation of the ethanol organosolv process for wood chips, in the wider context of bioethanol production, including a boiler for utilities. Therefore, processing steps for the simulation were based on ref 42, key process parameters defined in Table 2, and performance variables defined in Table 3. All utilities employed during the simulation follow heuristics given by refs 46 and 47 . Table 4 and Figure 2 to 7 outline the main stages and steps of the organosolv process. Further references for individual stages are given in Table 4.

Table 4. Process simulation stages for the ethanol organosolv process on EFB.

Stage Main steps

Stage $0 \quad$ EFB drying and comminution ${ }^{46,48-50}$

Wet EFB [BIOMASS] with moisture content $67 \mathrm{wt} \%$ at ambient conditions is dried to

$7 \mathrm{wt} \%$ in dryer D-1. Evaporated water and dried biomass at flow rate of 10 tons/hour 
is released. Biomass is cooled to $40{ }^{\circ} \mathrm{C}$ in cooler $\mathrm{C}-1$ and milled in grinder G-1. See Figure 2 .

Stage $1 \quad$ Feed mixing and pressurisation ${ }^{47,51}$

EFB is mixed with the solvent mixture and pressurised to 40 bar. The belt conveyer P-1 simplified the solid handling process. Quantities of fresh water and fresh ethanol were determined taking into account solvent recovery [DISTILL3], washing requirements for [SOLVENT1] and the liquid to solid ratio. [SOLVENT2] is mixed with a pressurised acid catalyst and pressurised biomass at 1.1 bar in mixer M-2. The slurry [S1] is pumped to the digester pressure of 40 bar using slurry pump P-5. See Figure 3.

Stage 2 Fractionation and cellulose recovery ${ }^{43,51}$ Slurry [S2] is preheated to $210^{\circ} \mathrm{C}$ in heater $\mathrm{H}-1$ before entering the digester (digester at $40 \mathrm{bar}, 210{ }^{\circ} \mathrm{C}$, residence time of 90 minutes, under agitation). Solvent mixture disrupts the hemicellulose-lignin matrix. The digester effluent is cooled in C-2 to ambient conditions and separated by a centrifuge filter into cellulose pulp [PULP] and liquor [LIQ], containing solvent, lignin, cellulose, and hemicellulose oligomers as well as xylose. The pulp is then washed in WASH-1 with additional solvent [SOLVENT 1] from Stage 1 to remove soluble lignin fragments and in WASH-2 with water to displace 70\% of ethanol. [SOLVENT3] and [WATER6] are assumed to be wasted. The washed pulp [PULP3] is dried to moisture content of $10 \mathrm{wt} \%$ in D-2 to remove the solvent load, giving cellulose product at required purity and recovery. See Figure 4 .

Stage 3 Precipitation and lignin recovery ${ }^{43,52,53}$

[LIQ] from filter in stage 2 is diluted with [WATER3] in 2:1 volumetric ratio to precipitate lignin in a precipitation tank [PRECIP] at room temperature and a 
residence time of 60 minutes. The effluent undergoes centrifuge filtration [FILTER2], is washed with fresh water in WASH-3 and dried in D-7 to a moisture content of 10 wt\% final lignin product at required purity and recovery. [WATER8] is assumed to be wasted. See Figure 5.

\section{Stage $4 \quad$ Solvent recovery and xylose concentration ${ }^{42,43}$}

[LIQ4] from stage 3 is fed into a distillation column [COLUMN] at the $18^{\text {th }}$ stage. Nearly $99.9 \%$ of ethanol is recovered in [DISTILL] and recycled back to stage 1 . Water recovery was also adjusted to satisfy solvent requirements in stage 1 . The [BOTTOMS] stream undergoes a sequence of evaporations to concentrate xylose. At a moisture content of $85 \mathrm{wt} \%$ tarry low molecular weight lignin solidifies and forms an organic phase which can be decanted. In DECANTER, $60 \%$ of low molecular weight lignin was simulated to enter the organic phase [LMWLIG] with a purity of 70 wt\%. Remaining lignin is present in the aqueous phase with xylose (at required purity and recovery) and water. See Figure 6.

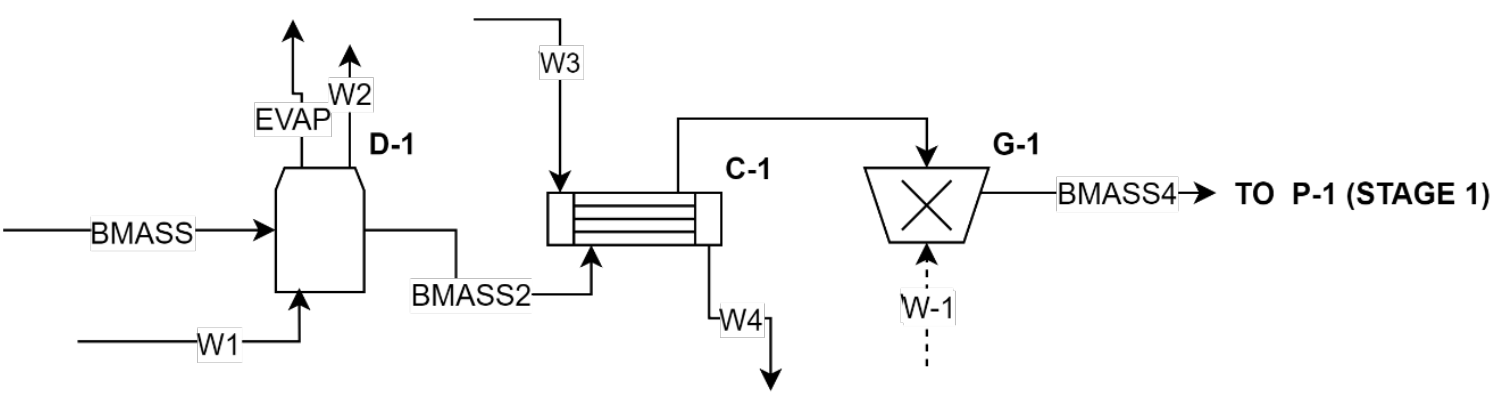

Figure 2. Process diagram of stage 0 . EFB drying and comminution. 


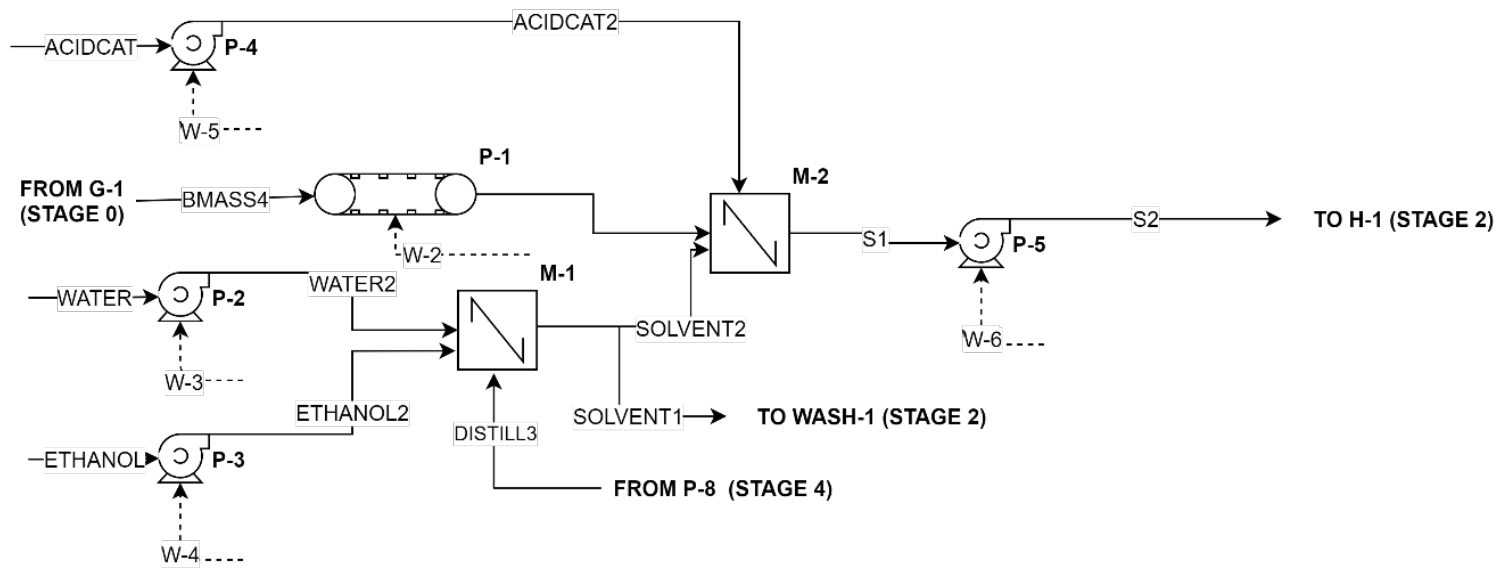

Figure 3. Process diagram of Stage 1. Feed mixing and pressurisation.

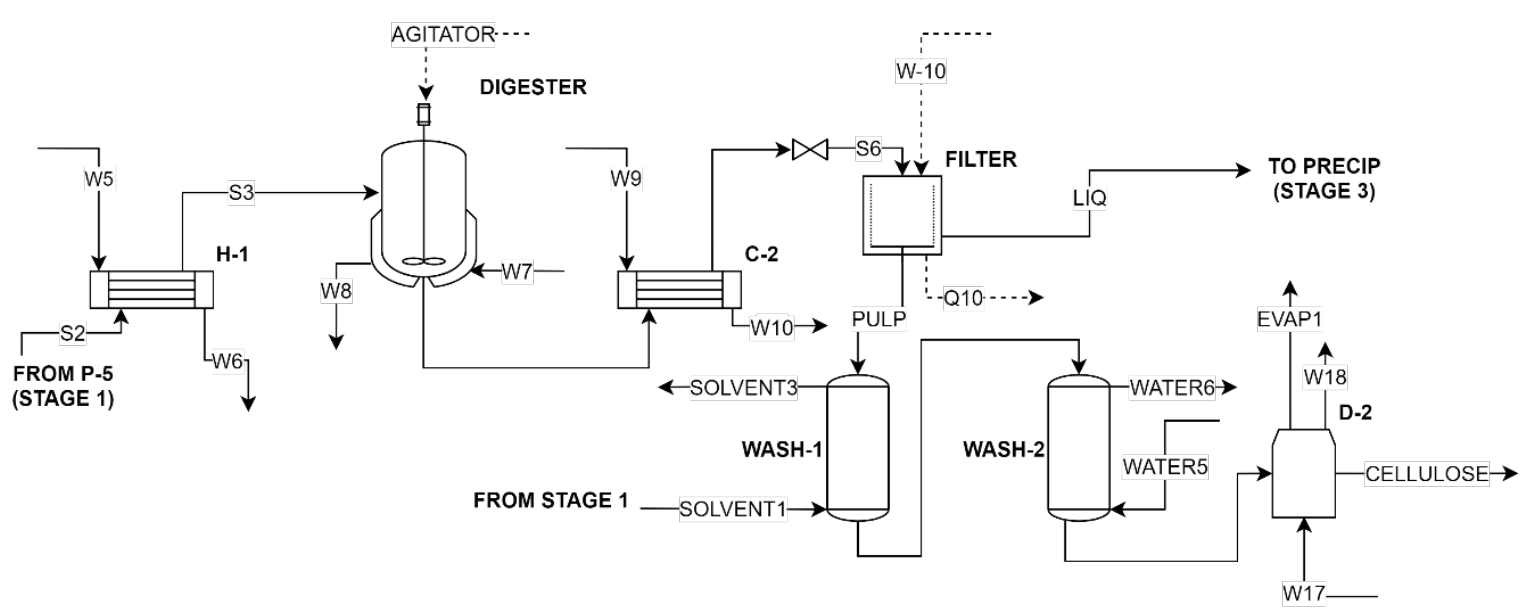

Figure 4. Process diagram of Stage 2. Fractionation and cellulose recovery. 


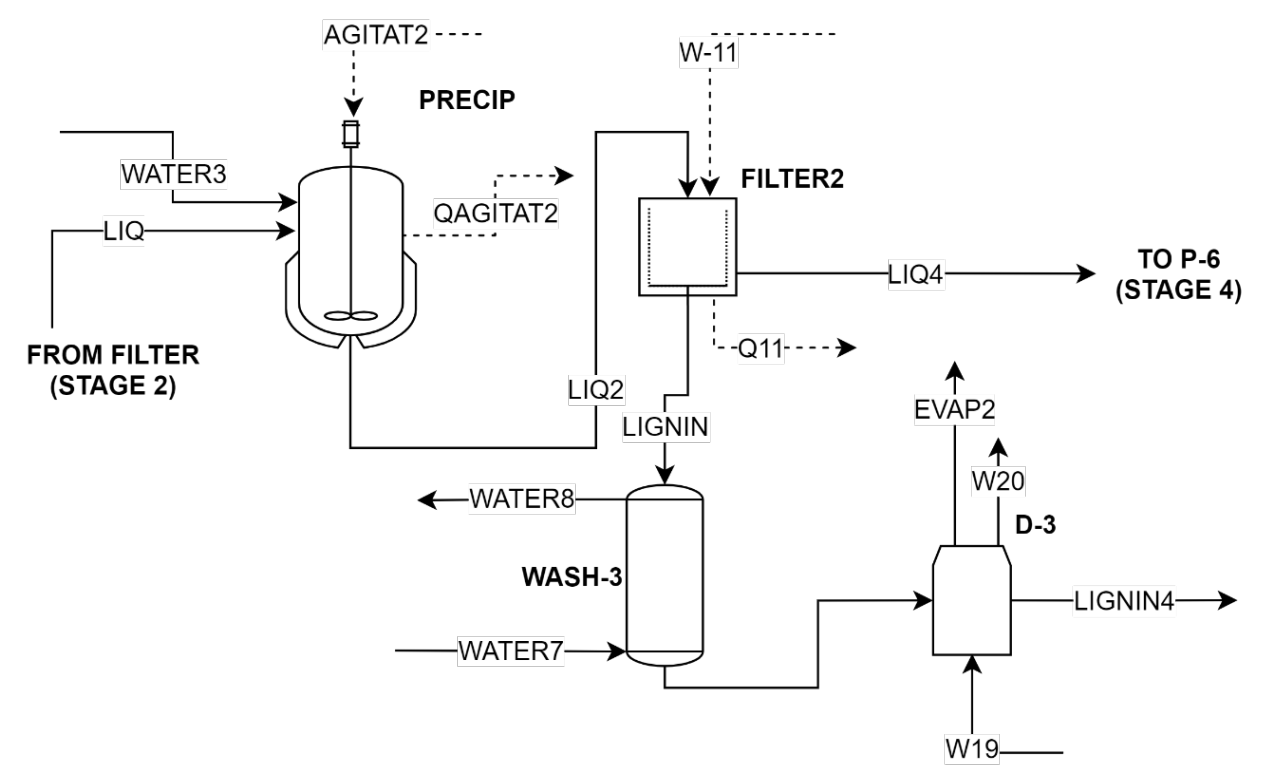

Figure 5. Process diagram of Stage 3. Precipitation and lignin recovery.

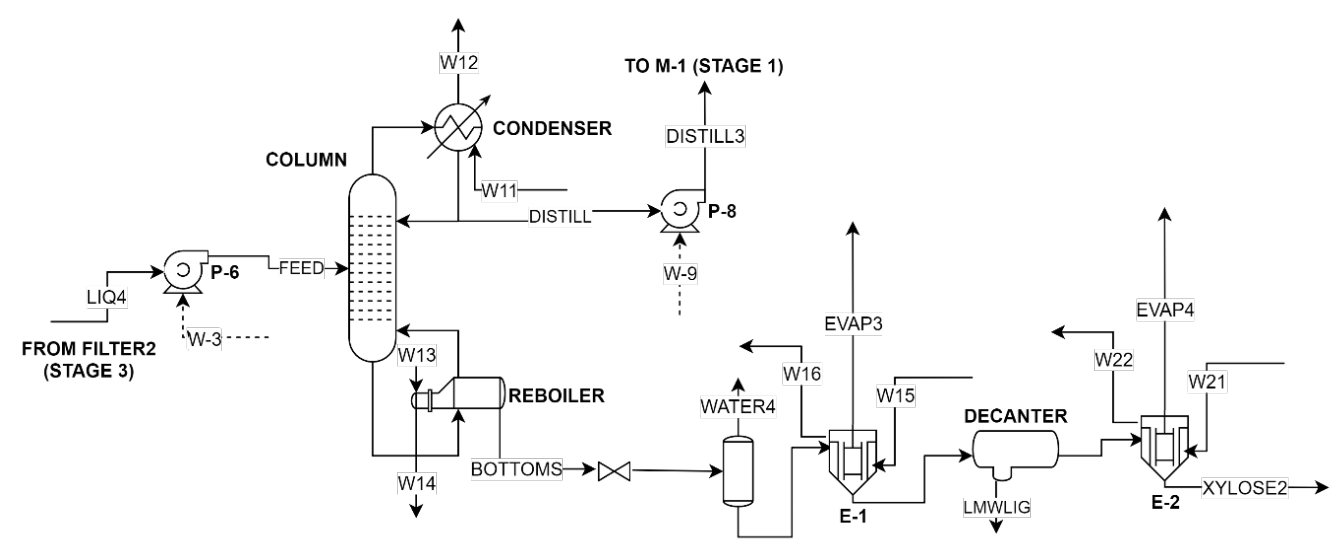

Figure 6. Process diagram of Stage 4. Solvent recovery and xylose concentration.

Previous literature indicated a boiler unit for utilities. ${ }^{42}$ Thus, the boiler simulation is presented additionally in Figure 7. A combustor unit [COMB-1] and a heater [B-1] represent the boiler unit. As cleanest burning fossil fuel, methane [METHANE] is supplied at $15{ }^{\circ} \mathrm{C}$ and 20 bar. The [METHANE] pressure is lowered in a valve to 1.3 bar and mixed with precompressed air. A complete combustion of methane was assumed in COMB-1 at an oxygen 
excess rate of $20 \%$. Steam is generated from the exchange of the hot products from the combustor [PROD] with feedwater from various process units. B-1 is assumed to operate at $80 \%$ efficiency, with the heat loss [QLOSS] and the flue gas is assumed to be wasted.

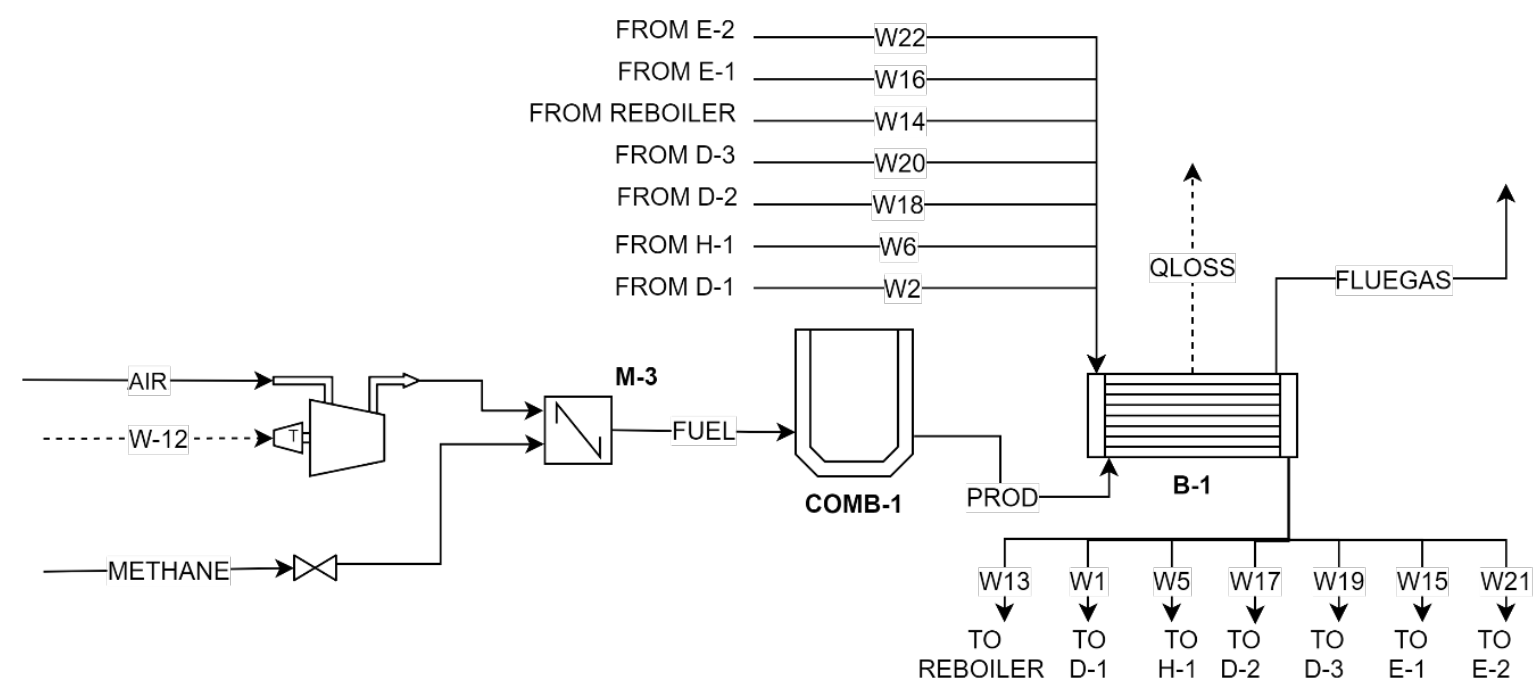

Figure 7. Process steam boiler information.

\subsection{Exergy analysis}

With the simulation complete, the methodology for exergy analysis in accordance with aim (d) is detailed in this section. The workflow to obtain exergy values has been presented in the earlier literature. Mabrouk et al. calculated exergy balances over mixer, heater, reactor and filtration units for the treatment of olive-residue with an organosolv process and discovered that biggest exergy destruction is attributed to the reactor. ${ }^{24}$ Similarly, Ofori-Boateng et al. found the largest contribution of exergy destruction for reactor heating for the case study of oil palm fronds. ${ }^{25}$ Despite the inclusion of a solvent recovery column in the organosolv process for sugarcane bagasse, Ortiz et al. calculated a lower exergy efficiency than Ofori-Boateng et al. ${ }^{25,26}$ Aghbashlo et al. ${ }^{28}$ simulated a lactic acid biorefinery using sugarcane bagasse as the substrate, and steam explosion as the pretreatment process. Although the organosolv 
process was not explored, unlike in other studies, a boiler unit with fuel combustion for hot utilities was included. An exergy analysis revealed the lowest exergy efficiency of all studies, less than $50 \%$, with most exergy destruction traced to the boiler unit.

To the best of our knowledge, there are no exergetic studies of an ethanol organosolv process for EFB from Malaysia or Indonesia that have considered all main processing steps, including the boiler unit. However, the fundamental workflow across these works is similar. To describe the exergy of a chemical process, we can differentiate between exergy related to matter flow and exergy which is not related to matter flow. The latter is thermal exergy $\left(E x_{h}\right)$ as a result of thermal energy transfer and work here described as shaft work $\left(E x_{W_{S}}\right)$.

$$
\begin{aligned}
& E x_{h}=\left(1-\frac{T_{0}}{T}\right)(Q) \\
& E x_{W_{s}}=W_{s}
\end{aligned}
$$

where $T_{0}$ is the temperature of the environment, $T$ is the temperature of the process, $Q$ is the transferred heat, and $W_{s}$ is the shaft work. We define the reference environment as $1 \mathrm{~atm}$ and $25^{\circ} \mathrm{C}$.

Exergy relating to matter flow is the sum of physical $\left(E x_{p h}\right)$, chemical $\left(E x_{c h}\right)$, kinetic $\left(E x_{k}\right)$ and potential exergies $\left(E x_{p}\right)$. However, kinetic and potential exergies may be neglected in the case of chemical reactions due to data shortage on the exact process layout, ${ }^{14}$ rendering:

$$
E x_{f}=E x_{p h}+E x_{c h}
$$

Chemical exergy reflects differences in composition of a stream relative to the reference environment. The chemical exergy obtained in the standard state, is called the standard chemical exergy and can be computed for any species $i$ by 


$$
E x_{c h, i}^{\circ}=\Delta G_{\mathrm{f}}^{\circ}+\sum_{e l} n_{e l} e x_{c h, e l}^{\circ}
$$

where $E x_{c h, i}^{\circ}$ is the standard chemical exergy of species $i, \Delta \mathrm{G}_{\mathrm{f}}^{\circ}$ is the Gibb's free energy at reaction of formation and $n_{e l}$ is the number of atoms of element $e l$ with mol specific standard chemical exergy of the element $e x_{c h, e l}^{\circ} .{ }^{54}$ We define the reference environment with mean concentrations of reference compounds in the surrounding environment specified by Szargut et al. ${ }^{55}$ Note that the reference state for all elements is not the actual natural environment, but a state that represents the most devaluated form of the elements. ${ }^{56,57}$

Standard chemical exergies for common and simple components, e.g. carbon dioxide, ethanol, nitrogen, have already been calculated in previous literature using Eq. (4) and can be taken from tabulated works. ${ }^{54,55}$ For complex materials such as biomass, $\Delta G_{\mathrm{f}}^{\circ}$ is difficult to obtain. ${ }^{14,58}$ Previous works have established correlation functions for specific types of molecules. Herein, we utilise the direct correlation from elemental compositions introduced by Shieh et al. to obtain values for cellulose, hemicellulose, lignin and xylose..$^{59}$

For a stream of one component, the chemical exergy equals the standard chemical exergy of the component, while for multiple chemical species the weighted sum over all stream components is applied taking mixing behaviour into account.

$$
e x_{c h}=\sum_{i} x_{i} e x_{c h, i}^{\circ}+\frac{R T_{0} \sum_{i} x_{i, n} \ln \left(\gamma_{i} x_{i, n}\right)}{\bar{M}}
$$

where, $e x_{c h}$ is the mass specific chemical exergy of a stream, $x_{i}$ is the mass fraction and $e x_{c h, i}^{\circ}$ is the mass specific standard chemical exergy of component $i . R$ is the universal gas constant, $x_{i, n}$ is the mole fraction of component $i, \gamma_{i}$ is the activity coefficient of component $i$ in the solution and $\bar{M}$ is the average molecular mass. The second term in Eq. (5) refers to the exergy 
destruction as a result of solution mixing and is analogous to the Gibb's energy change of mixing. In the case of ideal mixing, as is the case for the solids in the system, $\gamma_{i}$ is 1 . For mixtures of gases, the molar fraction in the gaseous phase, $y_{j, n}$ and the fugacity coefficient, $\phi_{\mathrm{j}}$ are used instead of $x_{j, n}$ and $\gamma_{j}$ respectively.

The specific mass physical exergy of a stream, $e x_{p h}$, can be calculated using Eq. (6) and includes enthalpy, $\left(h-h_{0}\right)$, and entropy, $\left(s-s_{0}\right)$, differences as a result of temperature and pressure changes with respect to the reference environment.

$$
e x_{p h}=\left(h-h_{0}\right)-T_{0}\left(s-s_{0}\right)
$$

Additional terms based on the state and phase, e.g. evaporation enthalpy, and deviations from ideality, are captured by the NRTL-RK property package in APSEN Plus. Thus, physical exergy values are directly extracted from the software. Based on the different types of exergy covered, all relevant stream data (flow, heat, and work) were exported, including $e x_{p h}$ values. The chemical exergy for each stream was calculated using Eq. (5). The required mass and molar fractions of components as well as the activity/fugacity were obtained from the ASPEN Plus database and simulation and the standard chemical exergies of compounds were retrieved using tabulated values and the correlation function of Shieh et al. . $^{5455,59}$

Metrics such as the exergy destruction, exergy loss, cumulative exergy demand and exergetic efficiency can indicate the resource intensity and efficiency of a process. Eq. (7) provides the exergy balance, where indices in indicate incoming exergies and out outgoing exergies. The Right-Hand-Side of Eq. (7) is described as term $I$ and records the amount of exergy destruction within the system which accounts for entropy generation $S_{g e n}$.

$$
\sum E x_{f, \text { in }}-\sum E x_{f, o u t, p}-\sum E x_{f, o u t, w}+\sum E x_{h, \text { in }}-\sum E x_{h, \text { out }}+\sum E x_{w s, \text { in }}=T_{0} S_{g e n}=I
$$


The exergy loss describes the exergy leaving the system as a waste stream, $\sum E x_{f, o u t, w}$, and the cumulative exergy demand, $C E x_{d}$, is the exergy which is used as input to the system, see Eq. (9). The exergetic efficiency, $\eta_{\text {ex }}$ see Eq. (10), is the ratio of useful exergy outlet over exergy inlet.

$$
\begin{aligned}
& C E x_{d}=\sum E x_{f, \text { in }}+\sum E x_{h, \text { in }}+\sum E x_{w s, i n} \\
& \eta_{e x}=\frac{\sum E x_{f, o u t, p}+\sum E x_{h, o u t}}{C E x_{d}}
\end{aligned}
$$

All exergy calculations were done on an Excel worksheet with exported stream data from the simulation as well as literature values. It is important that for future integration of waste materials into reaction networks, predictive methods based on early-stage data or automated simulations are developed and full datasets and models for any published itineraries are available.

\section{Results and Discussion}

\subsection{Biowaste identification}

As per aim (a), biowaste sources in the region of Singapore, Malaysia and Indonesia need to first be identified. Outlined by the statistics from National Environment Agency (NEA) in Singapore ${ }^{60}$ nearly 7.2 million tons of solid waste were generated in Singapore in 2019. Waste types generated were, in million tons (MT):

- Construction and demolition (1.440 MT),

- Ferrous metal (1.278 MT),

- Paper/cardboard (1.011 MT), 
- Plastics (0.930 MT),

- Food (0.744 MT,

- Wood (0.438 MT),

- Horticultural (0.400 MT),

- Ash \& sludge (0.252 MT),

- Textile/leather (0.168 MT),

- Used slag (0.129 MT),

- Non-ferrous metal (0.126 MT),

- Glass (0.075 MT),

- Scrap tires (0.033 MT),

- $\quad$ and others (0.210 MT).

Relevant to production of value-added chemicals are biological waste sources containing complex and highly functionalized feedstocks. Main sources of such molecules are lignocellulosic waste (paper/cardboard, wood, and horticultural) and food waste. Wood waste include crates, boxes, wooden planks used in construction, furniture and pallets, and horticultural waste includes tree trunks, branches, plant parts, trimmings. Food waste comprises domestic waste (households and residential complexes) as well as non-domestic (for instance restaurants, hotels, shopping malls). Other waste types, such as ferrous metal or construction debris, either lack the desired molecular structures, or are generated in rather small quantities.

Another significant area of opportunity lies with Singapore's neighbours, Malaysia and Indonesia, which have large agricultural activities and an abundance of lignocellulosic waste from these. Notably, both countries together account for $85 \%$ of global production for crude 
palm oil, which originates from the oil palm crop. ${ }^{61}$ More than $80 \%$ of the oil palm is disposed as biowaste, making it a promising source. ${ }^{62}$ Due to the close proximity and large availabilities, research efforts aiming to valorize oil palm biowaste have also gained traction in Singapore. 63

\subsection{Biowaste characterization and evaluation}

Having identified some of the prominent waste streams in the region, we can now apply the five criteria outlined in Table 1 in Section 2.1 to characterize and evaluate them, as per aim (a). A total of 2.6 million tons of biowaste is generated in Singapore per annum with an overall recycling rate of $45 \%$, see values for 2019 in Table 5. Note, that recycled material in the NEA statistics also accounts for cogeneration of steam and energy for chemical industries and for co-digestion with water sludge for biogas production. Material used in Waste to Energy (WtE) plants is recorded as non-recycled. High quantities for lignocellulosic waste as well as for food waste have been stable over the last four years as outlined in Figure 8, indicating that criteria (1) and (2) are met.

Table 5. Biowaste availabilities (million tons per annum (MT/a)) and recycling rates (Percentage) in Singapore.

\begin{tabular}{llll}
\hline Waste type & Generated (MT/a) & Recycled (MT/a) & Recycling rate (\%) \\
\hline Paper/cardboard & 1.011 & 0.450 & 44.5 \\
Horticultural & 0.400 & 0.293 & 73.3 \\
Wood & 0.438 & 0.289 & 66 \\
\hline
\end{tabular}




\begin{tabular}{lccc}
\hline Total lignocellulosic waste & 1.849 & 1.032 & 55.8 \\
Total food waste & 0.744 & 0.137 & 18.4 \\
\hline Total biowaste & 2.593 & 1.169 & 45.1
\end{tabular}

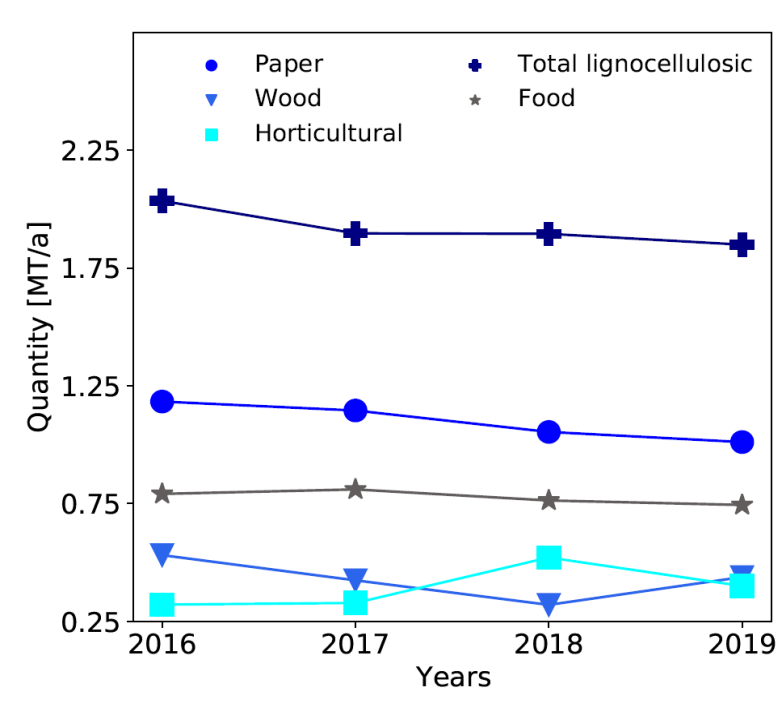

(a)

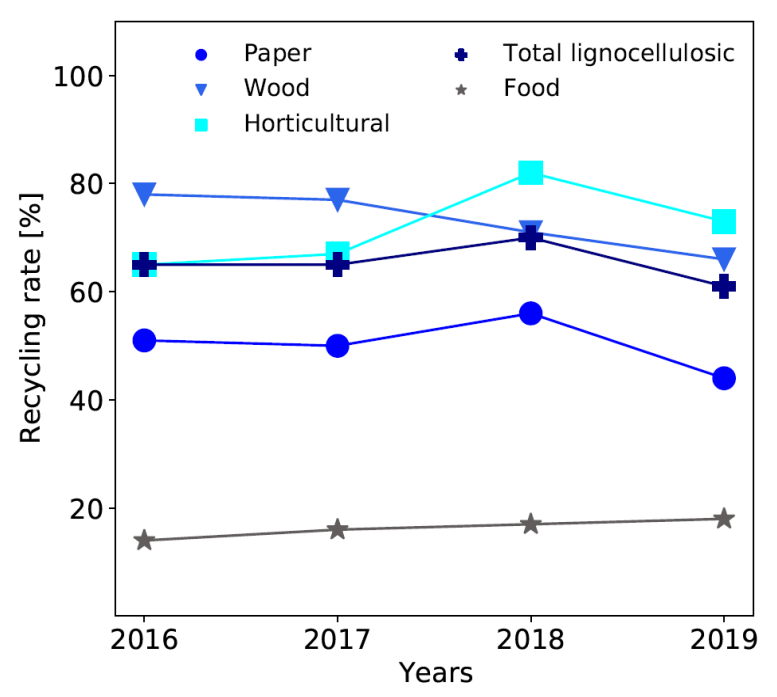

(b)

Figure 8. Stability of waste source supply. (a) Generation of different types of waste between 2016 and 2019 in Singapore in million tons per annum (MT/a). (b) Percentage of waste source recycling.

\section{Food waste}

Singapore generates 744,000 tons of food waste per annum (stable from year to year) from which only 18\% were recycled in 2019 as shown in Table 5, fulfilling criteria (1), (2) and (3). However, the segregation of feedstocks from food waste (criteria (4)) poses significant challenges and remains the main reason for low food recycling rates. Food waste requires three steps of segregation: firstly, a separation of food waste from mixed waste streams, secondly, a separation into food waste fractions (e.g. seafood shell waste, coffee grounds 
etc.), and thirdly, the isolation of feedstocks (pretreatment). $50 \%$ of the total food waste in Singapore comes from the domestic sector, where commonly the Central Refuse Chute system with only one waste disposal chute is used, making the first level of segregation at source problematic. Much of the non-domestic food waste is also not segregated at source and together with the domestic waste utilised for energy recovery in a Waste-to-Energy plant. However, some non-domestic waste sources enable the first level of segregation, which allows treatment onsite (e.g. food waste into compost) or treatment off-site (co-digested with water sludge for biogas conversion).

Some food manufacturers manage to segregate the first two levels so that food waste fractions, such as spent grain from breweries $\left(75,000 \mathrm{t} / \mathrm{a}{ }^{64}\right)$, bread waste and okara (soya bean curd residue from tofu production) $\left(11,000 \mathrm{t} / \mathrm{a}{ }^{65}\right)$, can be sold to recyclers, and converted into low-value animal feed. Important feedstocks from okara include cellulose, hemicellulose and lignin (explained in the next section); proteins which can lead to amino acid platform chemicals; and isoflavones (daidzein, genistein, glycitein). ${ }^{66}$ Spent grain can lead to not only cellulose, hemicellulose, lignin, and proteins but also triglyceride feedstocks which can yield fatty acids and glycerol platform chemicals; phytosterols; and phenolic acids (ferulic acid, p-coumaric acid). ${ }^{67-69}$ Other potential single-stream sources include used cooking oil from restaurants/fast food chains $\left(20,000\right.$ t/a $\left.{ }^{70}\right)$ which mostly contain triglycerides; fruit waste $\left(20,000 \mathrm{t} / \mathrm{a}^{71}\right)$ such as orange peels from juicing facilities which can yield terpenes such as limonene ${ }^{30,32}$, shown to lead to pharmaceuticals such as paracetamol ${ }^{72}$; spent coffee grounds $\left(6,300 \mathrm{t} / \mathrm{a}^{64}\right)$ which contain cellulose, hemicellulose, lignin and proteins; and seafood shell waste $\left(30,000 t / a^{73}\right)$ from seafood restaurant kitchens which contains chitin feedstocks that can be converted into nitrogen-rich chemicals ( $\mathrm{N}$-containing furan derivatives like 3acetamido-5-acetylfuran), pyrroles, amine/amide alcohols, amino acids, and organic acids. If 
chitin is deacetylated into chitosan, other platform chemicals such as 5hydroxymethylfurfural and lactic acid can be generated. ${ }^{74}$ Thus, given the large diversity of derivable feedstocks and potential platform chemicals, food waste also fulfills criteria (5).

Numerous start-ups, companies and research efforts ${ }^{71,75-77}$ are beginning to explore other avenues from these waste sources such as value-added food products, composite materials, and packaging, but chemicals remains a relatively unexplored area. Nevertheless, ease of segregation at large scale and easy perishability are still the major hurdle for food waste utilisation, and most of the identified waste sources are mixed and incinerated at present. Legislation allowing for food waste segregation (both first and second levels), continued research efforts, commercialization of food waste valorisation technologies, and dedicated single-stream collection infrastructure will be crucial in overcoming this limitation.

\section{Lignocellulosic waste}

Singapore generates 1.8 million tons of lignocellulosic waste per annum from which $56 \%$ were recycled in 2019 and which were relatively stable over the last four years, satisfying both criteria (1) and (2). This is true for both wood and horticultural waste, but paper/cardboard waste has experienced a slight decline (instability) with declining demand due to digitization.

The feedstocks in the lignocellulosic waste are represented by three types of biopolymers cellulose, hemicellulose, and lignin, which are each complex and can lead to numerous valueadded platform chemicals. Cellulose can be used for production of intermediates such as sorbitol, furans, alcohols by hydrolysis via glucose monomeric units. ${ }^{78}$ Hemicellulose on the other hand contains repeating C5 sugars, such as xylose, which can be used to produce xylitol, furfural, or ethanol (through fermentation). Value-added intermediates from both cellulose 
and hemicellulose include levulinic acid, glutamic acid, glucaric acid, itaconic acid, succinic acid, glycerol and 3-hydroxybutyrolactone. ${ }^{79}$ For the production of aromatic value-added molecules such as vanillin, catechol and cinnamic acid, lignin is most suited as it is the most abundant aromatic biopolymer. ${ }^{4}$ Therewith criteria (5) is also fulfilled.

To have a better understanding of the utilisation of lignocellulosic materials in Singapore, it is worthwhile to illustrate the ecosystem of waste usage. Figure 9 outlines the uses of lignocellulosic materials including percentages, based on the 2019 data. Paper and cardboard material from recycling bins partly separated at a central material recovery facility (MRF) from other recycling material (e.g. glass or plastics) and then further processed into pulp. Stained paper/cardboard or material above the facility occupancy is sent to WtE together with paper from the central chute. Wood can be upcycled into new products (e.g. furniture products), composted, or shredded into woodchips and used together with chips from horticultural waste to generate steam and electricity for industrial activities. The non-woody portion of the horticultural waste is composted. The use of the mixed wood chips for value-added chemicals is seen as problematic, as wood from consumer goods introduces significant impurities to the stream such as resigns and adhesives, bringing about challenges for criteria (4). Despite the possibilities of further substituting WtE treatment of lignocellulosic waste by material usage, the recycling system is well-established and economically viable and thus is failing criteria (3). 


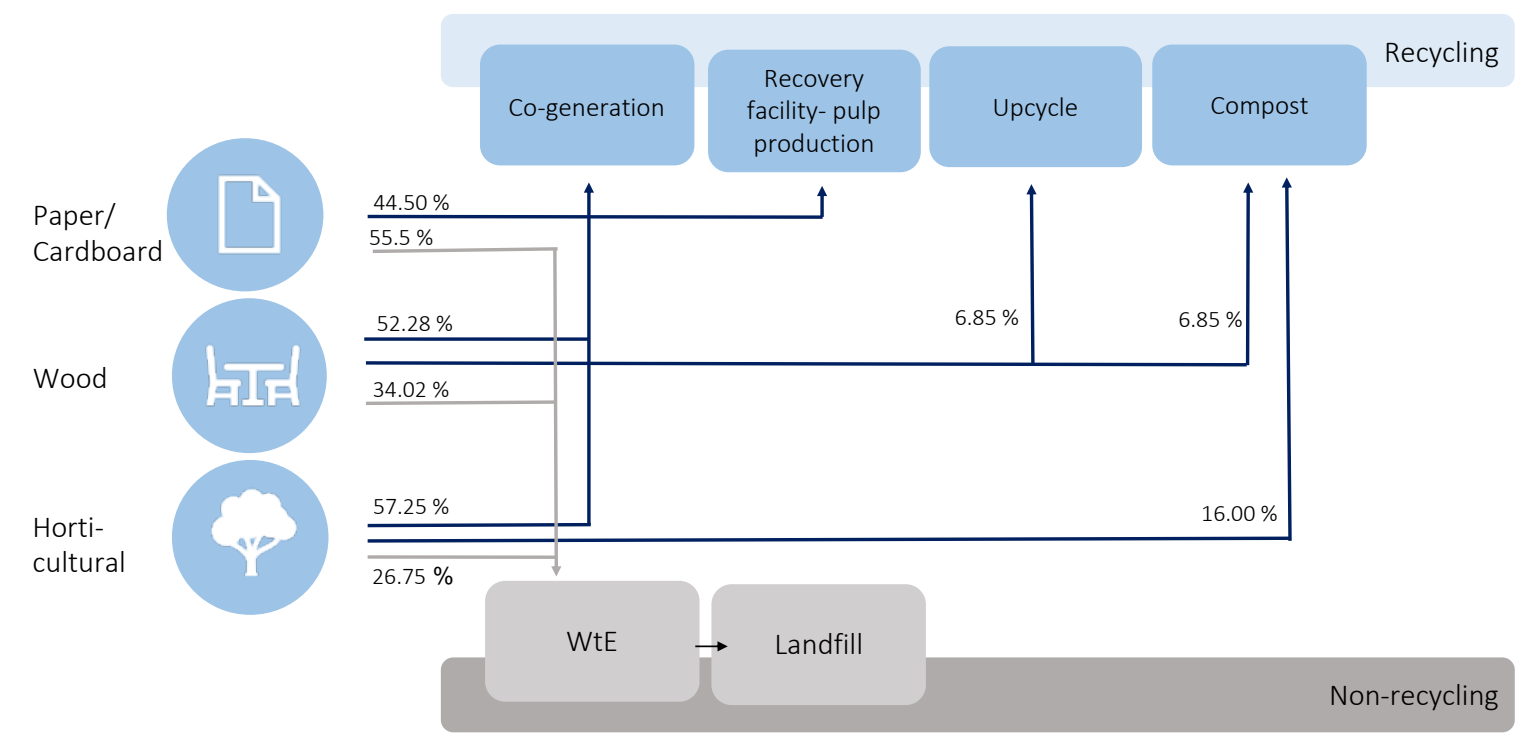

Figure 9. Waste utilisation ecosystem for lignocellulosic materials in Singapore in 2019. Approximate percentages are calculated after a discussion with the NEA, in which material streams for different recycling options were discussed. Note that ashes from WtE incineration are landfilled.

The other key type of lignocellulosic waste is agricultural in nature and found in Indonesia and Malaysia as oil palm biowaste. The reader is referred to ref. 80 for a more detailed treatment of the palm oil production process, and waste generation. In general, crude palm oil (CPO) is produced in oil palm plantations, with lignocellulosic solid waste residues being generated along the value chain, notably empty fruit bunch (EFB) leftover from the harvesting of fresh fruit bunch (FFB) from oil palms, mesocarp fiber (MF) leftover from squeezing the mesocarp to obtain palm oil, palm kernel shell (PKS) leftover from cracking the palm kernel, oil palm trunks (OPT), and oil palm fronds (OPF) left in the plantations. ${ }^{80}$ In 2019,100 million tons of Fresh Fruit Bunch (wet basis) were processed in Malaysia, producing 19.9 million tons of CPO ${ }^{81}$ Capacities are higher in Indonesia, with 236 million tons of FFB processed, producing 47 million tons of $\mathrm{CPO}^{82}$ Using known yields of oil palm biowaste from $\mathrm{FFB}^{62}$ as well as moisture contents of each type, the current dry-basis availabilities of each type of oil palm 
biowaste were calculated, and are summarized below in Figure 10 relative to other biowaste sources in Singapore.

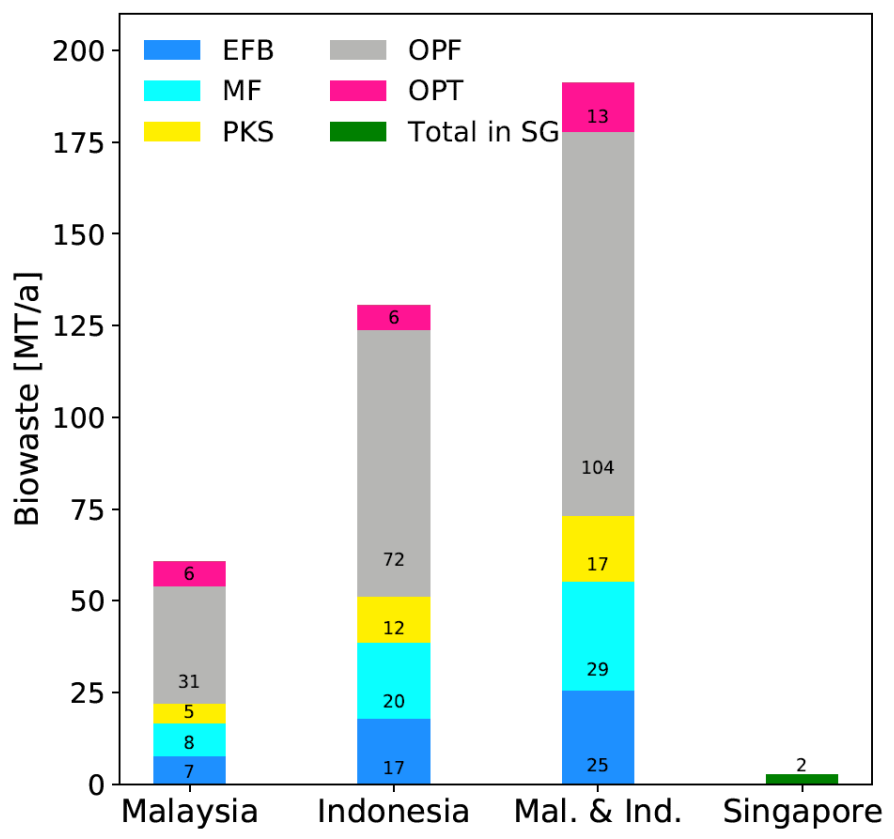

Figure 10. A comparison of oil palm waste availabilities (dry-basis) in Malaysia, Indonesia and total, with total biowaste availability (lignocellulosic and food waste) in Singapore. Individual quantities in MT/a are shown as labels.

As shown above, the combined availability of dry oil palm biowaste in Indonesia and Malaysia is more than 70 times higher than total biowaste available domestically in Singapore (191 million tons against 2.6 million tons), performing well in criteria (1) and allowing for economies of scale. Looking at specific oil palm biowaste streams, MF and PKS are already well utilized as boiler fuel in oil palm mills as they have a low moisture content, thus falling short in criteria (3). OPT and OPF while underutilized and highest in availability, ${ }^{80}$ are dispersed across the plantation, requiring extensive labor to collect, potentially impacting supply stability and criteria (2). ${ }^{4,83} \mathrm{EFB}$, on the other hand, is an unavoidable waste stream from the milling process at palm oil factories, easy to collect, already segregated, and with no 
widely established further use (mainly mulch, compost and landfill material). ${ }^{84-86}$ EFB contains the feedstock biopolymers lignin, cellulose and hemicellulose, and its availability is estimated at 26 million tons/year, which is almost ten times higher than the total available biowaste quantity in Singapore, and is expected to stay stable or increase with projected growing global palm oil demand. ${ }^{87}$ Thus, EFB fulfills all waste criteria. Note that within the context of deforestation and clearing of peatlands for the expansion of plantations, it is important to utilize EFB solely from strictly controlled sustainable farms.

\subsection{Biowaste selection}

In accordance with aim (2) and based on the characterization results discussed in the previous sections and summarized in Table 6, EFB was selected for further pretreatment process analysis.

Table 6. Summary of characterization data based on the five criteria for identified biowaste sources in and around Singapore. Chosen biowaste source is highlighted in green, and important unfavourable criteria are highlighted in red.

\begin{tabular}{|c|c|c|c|c|c|}
\hline Criteria & $\begin{array}{l}\text { Availability } \\
\text { (MT/a) }\end{array}$ & $\begin{array}{l}\text { Supply } \\
\text { stability }\end{array}$ & Underutilization & Segregation/purity & $\begin{array}{l}\text { Relevant } \\
\text { feedstocks }\end{array}$ \\
\hline $\begin{array}{l}\text { Food Waste } \\
\text { (Section } 3.2 \\
\text { lists relevant } \\
\text { food waste } \\
\text { fractions) }\end{array}$ & 0.7 & Stable & $\begin{array}{l}\text { Lowest recycling } \\
\text { rate }(18 \%)\end{array}$ & Mixed & $\begin{array}{l}\text { Diverse feedstocks } \\
\text { (cellulose, } \\
\text { hemicellulose, } \\
\text { lignin, protein, } \\
\text { chitin, } \\
\text { triglycerides, }\end{array}$ \\
\hline
\end{tabular}




\begin{tabular}{|c|c|c|c|c|c|}
\hline & & & & & $\begin{array}{l}\text { terpenes, } \\
\text { phytosterols, } \\
\text { flavonoids,etc.) }\end{array}$ \\
\hline $\begin{array}{l}\text { Wood, } \\
\text { horticultural } \\
\text { waste }\end{array}$ & 0.8 & Stable & High recycling & Impure & $\begin{array}{l}\text { Cellulose, } \\
\text { Hemicellulose, } \\
\text { Lignin }\end{array}$ \\
\hline $\begin{array}{l}\text { Paper/ } \\
\text { cardboard } \\
\text { waste }\end{array}$ & 1.0 & $\begin{array}{l}\text { Declining } \\
\text { demand }\end{array}$ & rate $(55.8 \%)$ & $\begin{array}{l}\text { Able to be } \\
\text { segregated in MRF }\end{array}$ & Mostly cellulose \\
\hline EFB & 25.6 & $\begin{array}{l}\text { Stable, and } \\
\text { growing }\end{array}$ & $\begin{array}{l}\text { Underutilized as } \\
\text { compost/mulch/ } \\
\text { landfill material }\end{array}$ & Segregated & $\begin{array}{l}\text { Cellulose, } \\
\text { Hemicellulose, } \\
\text { Lignin }\end{array}$ \\
\hline MF, PKS & 47.6 & $\begin{array}{l}\text { Stable, and } \\
\text { growing }\end{array}$ & $\begin{array}{l}\text { Utilized as boiler } \\
\text { fuel }\end{array}$ & Segregated & $\begin{array}{l}\text { Cellulose, } \\
\text { Hemicellulose, } \\
\text { Lignin }\end{array}$ \\
\hline OPF, OPT & 118.1 & $\begin{array}{l}\text { Plantation- } \\
\text { wide } \\
\text { collection } \\
\text { needed }\end{array}$ & $\begin{array}{l}\text { Underutilized as } \\
\text { compost/mulch/ } \\
\text { landfill material }\end{array}$ & Segregated & $\begin{array}{l}\text { Cellulose, } \\
\text { Hemicellulose, } \\
\text { Lignin }\end{array}$ \\
\hline
\end{tabular}

As an extension of criteria (5), it is important to understand the chemical composition of EFB in more detail and its feedstock makeup. This poses a challenge, as composition depends on maturity (age) of the oil palm, soil conditions, weather, species, growth conditions and duration of storage. As an approximation, the composition of EFB has been calculated by averaging the results of six studies ${ }^{88-93}$ as shown in Table 7. 
Table 7. Averaged wet and dry composition of EFB sourced from Indonesia and Malaysia.

EFB Component Wet composition (\%) Dry composition (\%)

Cellulose

12.0

33.8

Hemicellulose

7.0

19.6

Lignin

9.2

25.9

Ash

1.3

3.6

Extractives

3.5

10

Total (ash, extractives)

4.8

13.6

Moisture

67

7 


\subsection{Exergy analysis}

Results have been obtained by applying the methodology specified in Section 0 for exergy analysis. The simulation of the EFB treatment resulted in following product recoveries, purities, and yields (Table 8).

Table 8. Product recovery, purities and yields of the organosolv process for EFB.

\begin{tabular}{llll}
\hline Products & Recovery & Purity & Actual yield (ton product/ton \\
& & & wet EFB) \\
\hline Cellulose & $80 \%$ & $75 \%$ & 0.096 \\
Lignin & $65 \%$ & $76 \%$ & 0.060 \\
Xylose & Appr. $80 \%$ & $28 \%$ & 0.057 \\
& & & \\
\hline
\end{tabular}

Values are in accordance with the simulation of Mondylaksita et al. on which input parameters had been based. ${ }^{37}$ The low yields are due to the high moisture content of EFB and cellulose is produced at a higher rate as it is the dominant component in EFB.

It is important to note that although energetic analysis is important, it can be unreliable as it is based on the First Law of thermodynamics and is always conserved, disregarding entropy generation and internal irreversible losses as prescribed by the Second Law of Thermodynamics. Furthermore, it does not account for external losses embodied by waste streams. Exergy analysis is a useful alternative that can overcome these limitations, reflecting the quality or the fraction of energy that is utilizable and accounting for any losses. ${ }^{55,94}$ Exergy destruction, exergy loss, cumulative exergy demand and exergy efficiency are all potential 
metrics that can indicate the resource intensity and efficiency of a process, reflecting the environmental impact of a process more holistically than energy.

The exergy distribution over outlet flows for the simulated process can be seen in Figure 11. The cumulative exergy demand is made up from all incoming streams. Exergy is then either attributed to the products stream, the waste stream (external exergy loss), thermal outlets, or internal exergy destruction. Figure 11 outlines that only a small fraction of exergy is incorporated in the products here, and that most exergy is introduced to the process by methane combustion, rather than the biomass source. We will discuss reasons and hotspots for the limited exergy performance of the process in the following sections.

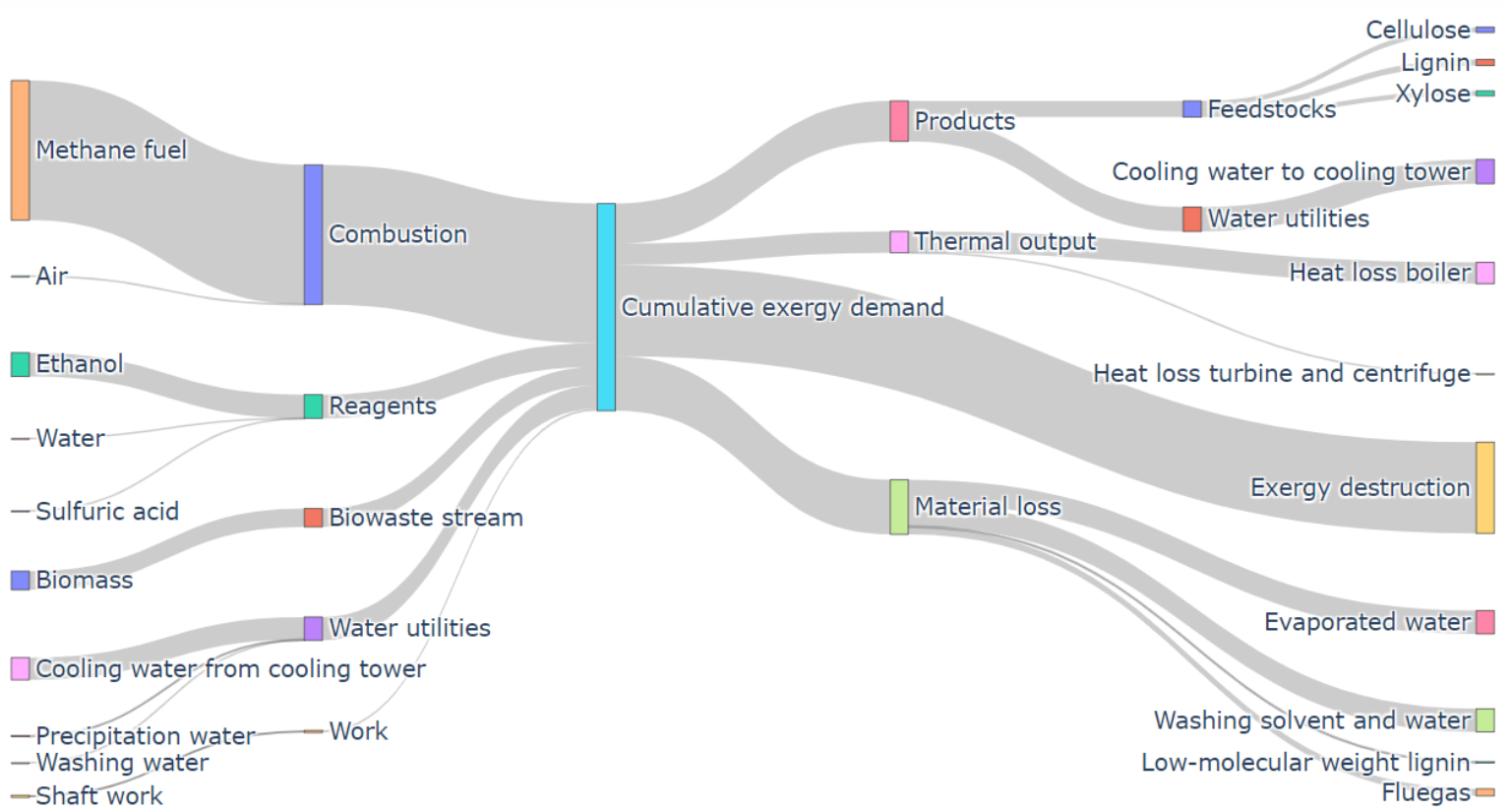

Figure 11. Exergy profile of the ethanol organosolv process. Incoming streams are categorised according to their use for combustion, as reagents, as biowaste, and as water or work utilities. All incoming streams make up the cumulative exergy demand, which is then split into products (feedstock biopolymers and water utilities), external loss as waste 
material, thermal output as heat, and internal exergy destruction. The input shaft work consists of work from grinder, pumps, centrifuge, agitators and turbines for reactor and precipitator. Note that the ethanol stream reflects fresh solvent required after taking into account solvent recycling which is not shown.

\section{Cumulative exergy demand}

The cumulative exergy demand per kg wet biomass is $80.9 \mathrm{MJ}$, which is 11 times more than the original exergy contained in the wet biomass feed. The cumulative demand for cellulose pulp is $631 \mathrm{MJ} / \mathrm{kg}$, for lignin is $1,029 \mathrm{MJ} / \mathrm{kg}$, and for xylose is $401 \mathrm{MJ} / \mathrm{kg}$. Viell et al. reported a cumulative energy demand of $28.8 \mathrm{MJ} / \mathrm{kg}$ biomass for wood chips. ${ }^{27}$ The lower value is likely due to the high moisture content in EFB as well as the inclusion of fuel requirements in exergy calculations in this study. Figure 12 illustrates a percentage breakdown of cumulative exergy demand across major process streams.

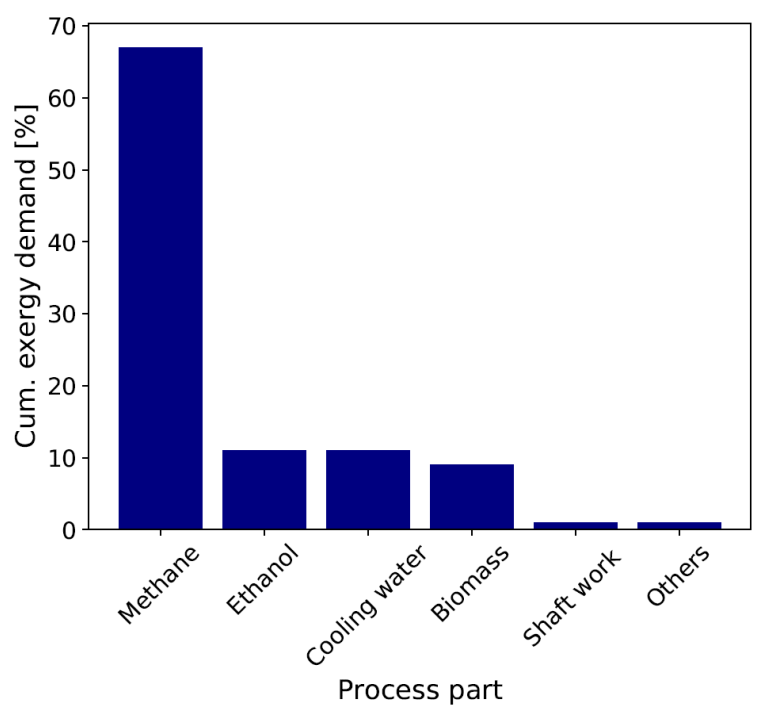

Figure 12. Percentage distribution of cumulative exergy demand across major streams in the ethanol organosolv process. 
In our study, $67 \%$ of the cumulative energy demand is due to methane, $11 \%$ each caused by ethanol and by cooling water and biomass input makes up $9 \%$ of the cumulative energy demand. The high liquid loads, which increase steam requirements, were identified to be the main cause for the high cumulative energy demand of methane and cooling water. In particular, nearly $84 \%$ of methane demand is split evenly between steam utilities required for the reboiler and $\mathrm{E}-1$, the evaporator following it and $80 \%$ of cooling water utilities is required to condense large vapor loads entering the condenser of the column. While the cumulative exergy demand of ethanol currently accounts for $11 \%$, it would account for $48 \%$ without solvent recovery. Future strategies should primarily focus on the reduction of fuel demand, e.g. by reducing liquid loads, and continue to decrease solvent demand.

\section{Exergy destruction, loss, and efficiency}

The destroyed exergy per $\mathrm{kg}$ of wet biomass is $35.6 \mathrm{MJ} / \mathrm{kg}$ and the lost exergy per biomass during the process is $21.2 \mathrm{MJ} / \mathrm{kg}$. The overall exergetic efficiency was calculated to be $30 \%$, which is significantly lower than previous studies that report efficiencies above $80 \%$ for the organosolv process on sugarcane bagasse and oil palm fronds. ${ }^{25,26} \mathrm{~A}$ breakdown of exergy destruction over all simulated process parts, see Figure 13 , elucidates that the majority of exergy destruction (74.43\%) is due to the boiler unit. Methane chemical exergy is destroyed during fuel combustion, generating entropy due to phase changes and high temperature gradients between heat exchanger and boiler feedwater. The approximate magnitude of boiler contribution to exergy destruction is in agreement with the work on lignocellulosic treatment by steam explosion by Aghbashlo et al. ${ }^{28}$ Previously mentioned works reporting an exergetic efficiency of over $80 \%$, have not included the boiler unit for utilities, which explains 
large deviations. We emphasize the relevance of the boiler utilities to prevent an inflated exergetic efficiency and reduced exergetic destruction.

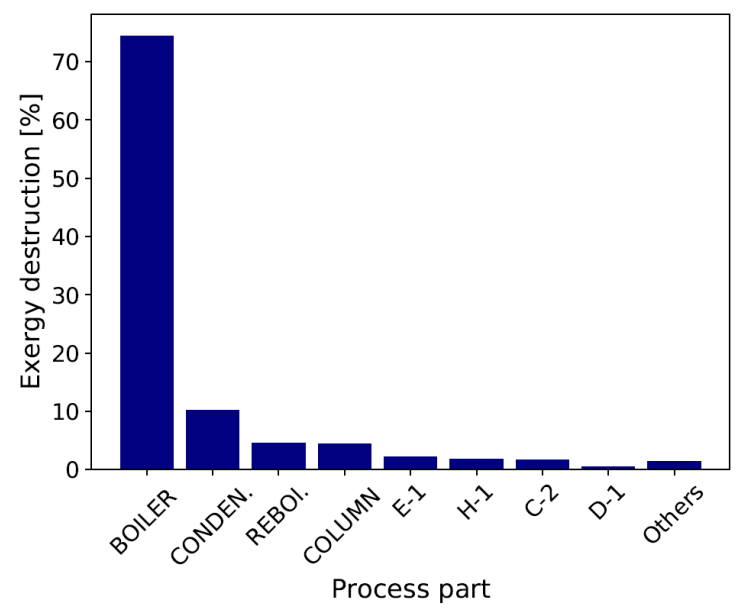

(a)

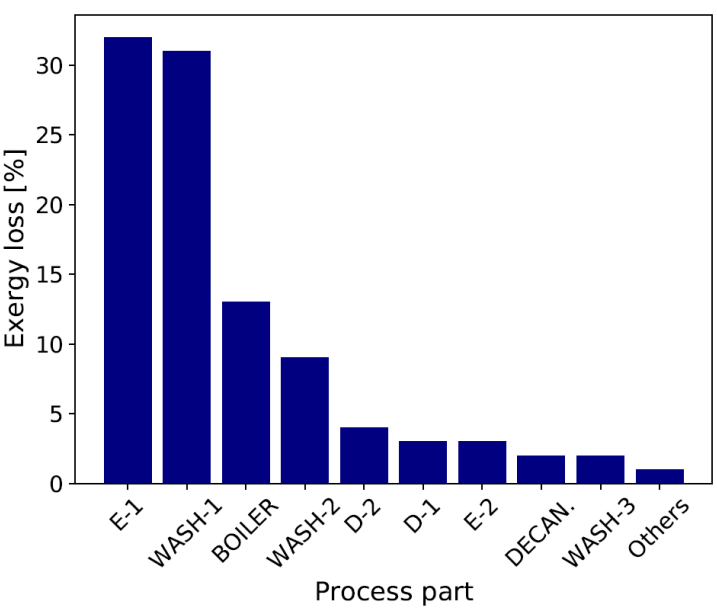

(b)

Figure 13. Distribution of exergy destruction (a) and exergy loss (b) over different parts of the organosolv process.

Process improvements should include heat recovery and heat integration e.g. by recovering heat from boiler flue gas as well as reducing vapor and liquid loads, e.g. by rigorous column optimization, minimizing solvent flows while preserving fractionation efficiency, or improving lignin precipitation in lower liquid-solid ratios.

With regards to the exergy loss, we find that nearly $32 \%$ are attributed to $E-1$, as 180 tons of water per hour are evaporated and lost in this unit. Another $31 \%, 9 \%$ and $2 \%$ of exergy loss are due to wasted solvent and wasted water in WASH-1, WASH-2 and WASH-3. However, there is a potential to address the above through better process integration, e.g. recycling SOLVENT3 to the digester or recycling between WASH-1 and WASH-2. If all waste streams are utilized and considered products, the exergy efficiency of the process can potentially increase to $56 \%$. 


\section{Conclusions}

Early-stage systematic approaches to integrate biowaste into reaction networks are needed for planning circular chemical supply chains. The regional dependency and heterogenous composition as well as extensive pre-treatment requirements of biowaste streams make their integration in early-stage screening methods challenging at present.

Therefore, a case study on Singapore and its neighbours was proposed to illustrate data requirements and workflows, structured around four aims. We first identify key biowaste sources, and characterize them using five criteria: availability, supply stability, underutilization, segregation/purity and derivable key feedstocks. We find that Singapore's neighbours have a significant amount of suitable empty fruit bunch (EFB) biowaste; easy to collect and stable in supply, possible to segregate, at present neither economically utilised nor properly managed from an environmental perspective, and able to yield useful feedstock such as cellulose, lignin and hemicellulose sugars. In the interest of extracting these feedstocks, an ethanol organosolv pretreatment process is then simulated in Aspen Plus using process conditions, parameters and steps from literature. An exergy profile is obtained from stream data which highlights opportunities for process improvement via metrics such as the cumulative exergy demand, exergy efficiency, exergy destruction and exergy loss.

The benefit of this study mainly lies in setting up future work, which should focus on scaling the methods outlined here across a wider range of regions, biowaste streams and pretreatment methods, leading to a pretreatment network. Exergy can be used as a common basis to integrate the pretreatment method with conventional reaction networks, allowing 
for holistic pathway screening. Greater granularity in regions and biowaste sources (e.g. food waste fractions) will also be needed, as well as automatable process simulations to yield exergy profiles. While the methods covered in this study are manual, they could set the basis for advanced techniques such as text mining for large scale data retrieval and crowdsourcing for filling in missing data wherever appropriate. The reader is referred to Figure S1 in the supplementary information for a brief depiction of a possible pretreatment network with the results of this case study.

\section{Conflicts of interest}

JMW, ZG and AAL are founders of CDI Pte Ltd and have commercial interest in the applications of reaction networks analysis tools.

\section{Acknowledgements}

AA acknowledges his PhD funding from Chemical Data Intelligence (CDI) Pte Ltd and Cambridge Centre for Advanced Research and Education in Singapore (CARES Ltd) within the grant C4T funded by National Research Foundation of Singapore within its CREATE programme. JMW acknowledges the Department of Chemical Engineering and Biotechnology at the University of Cambridge for her PhD studentship.

\section{References}

1 J. M. Weber, P. Lió and A. A. Lapkin, React. Chem. Eng., 2019, 4, 1969-1981.

2 B. A. Grzybowski, K. J. M. Bishop, B. Kowalczyk and C. E. Wilmer, Nat. Chem., 2009, 1, $31-36$. 
3 J. O. Metzger and U. Biermann, in Feedstocks for the Future, eds. J. J. Bozell and P. K. Martin, Oxford University Press, New York, USA, 2006, pp. 13-26.

4 C. O. Tuck, E. Pérez, I. T. Horváth, R. A. Sheldon and M. Poliakoff, Science (80-. )., 2012, $337,695-699$.

5 J. Clark and F. Deswarte, Introduction to Chemicals from Biomass: Second Edition, John Wiley \& Sons, Chichester, UK, 2015.

6 Z. Guo, N. Yan and A. A. Lapkin, Curr. Opin. Chem. Eng., 2019, 26, 148-156.

7 S. K. Bhatia, H. S. Joo and Y. H. Yang, Energy Convers. Manag., 2018, 177, 640-660.

8 A. T. Ubando, C. B. Felix and W. H. Chen, Bioresour. Technol., 2020, 299, 122585.

9 F. Fava, G. Totaro, L. Diels, M. Reis, J. Duarte, O. B. Carioca, H. M. Poggi-Varaldo and B. S. Ferreira, N. Biotechnol., 2015, 32, 100-108.

10 J. H. Clark, V. Budarin, F. E. I. Deswarte, J. J. E. Hardy, F. M. Kerton, A. J. Hunt, R. Luque, D. J. Macquarrie, K. Milkowski, A. Rodriguez, O. Samuel, S. J. Tavener, R. J. White and A. J. Wilson, Green Chem., 2006, 8, 853-860.

11 A. S. Nizami, M. Rehan, M. Waqas, M. Naqvi, O. K. M. Ouda, K. Shahzad, R. Miandad, M. Z. Khan, M. Syamsiro, I. M. I. Ismail and D. Pant, Bioresour. Technol., 2017, 241, 1101-1117.

12 A. Voll and W. Marquardt, AIChE J., 2012, 58, 1788-1801.

13 B. Bao, D. K. S. Ng, D. H. S. Tay, A. Jiménez-Gutiérrez and M. M. El-Halwagi, Comput. Chem. Eng., 2011, 35, 1374-1383.

14 P. M. Jacob, P. Yamin, C. Perez-Storey, M. Hopgood and A. A. Lapkin, Green Chem., $2017,19,140-152$. 
15 Y. L. Chiew, T. Iwata and S. Shimada, Biomass and Bioenergy, 2011, 35, 2925-2935.

16 L. Jayarathna, G. Kent, I. O'Hara and P. Hobson, Appl. Energy, 2020, 275, 115398.

17 K. Miezah, K. Obiri-Danso, Z. Kádár, B. Fei-Baffoe and M. Y. Mensah, Waste Manag., $2015,46,15-27$.

18 S. Soltanian, M. Aghbashlo, F. Almasi, H. Hosseinzadeh-Bandbafha, A. S. Nizami, Y. S. Ok, S. S. Lam and M. Tabatabaei, Energy Convers. Manag., 2020, 212, 112792.

19 M. Galbe and O. Wallberg, Biotechnol. Biofuels, 2019, 12, 294.

20 J. C. Romero and P. Linares, Renew. Sustain. Energy Rev., 2014, 33, 427-442.

21 G. Tsatsaronis, Chem. Eng. Technol., 1996, 19, 163-169.

22 S. Bilgen, S. Keleş and K. Kaygusuz, Energy, 2012, 41, 380-385.

23 J. M. Weber, Z. Guo, C. Zhang, A. Schweidtmann and A. A. Lapkin, Chem. Soc. Rev, 2021, doi:10.1039/D1CS00477H.

24 A. Mabrouk, X. Erdocia, M. G. Alriols, M. R. Jeday and J. Labidi, Appl. Therm. Eng., 2016, 106, 1062-1066.

25 C. Ofori-Boateng and K. T. Lee, Chem. Eng. J., 2013, 228, 162-171.

26 P. Silva Ortiz and S. de Oliveira, Energy, 2014, 76, 130-138.

27 J. Viell, A. Harwardt, J. Seiler and W. Marquardt, Bioresour. Technol., 2013, 150, 89-97.

28 M. Aghbashlo, M. Mandegari, M. Tabatabaei, S. Farzad, M. Mojarab Soufiyan and J. F. Görgens, Energy, 2018, 149, 623-638.

29 D. Esposito and M. Antonietti, Chem. Soc. Rev., 2015, 44, 5821-5835.

30 C. S. K. Lin, L. A. Pfaltzgraff, L. Herrero-Davila, E. B. Mubofu, S. Abderrahim, J. H. Clark, 
A. A. Koutinas, N. Kopsahelis, K. Stamatelatou, F. Dickson, S. Thankappan, Z. Mohamed, R. Brocklesby and R. Luque, Energy Environ. Sci., 2013, 6, 426-464.

31 B. J. H. Ng, Y. Mao, C. L. Chen, R. Rajagopal and J. Y. Wang, J. Mater. Cycles Waste Manag., 2017, 19, 560-569.

32 C. M. Galanakis, Trends Food Sci. Technol., 2012, 26, 68-87.

33 X. Zhao, S. Li, R. Wu and D. Liu, Biofuels, Bioprod. Biorefining, 2017, 11, 567-590.

34 K. Zhang, Z. Pei and D. Wang, Bioresour. Technol., 2016, 199, 21-33.

35 N. Ryan and P. Yaseneva, Philos. Trans. R. Soc. A, 2021, 379, 20200335.

36 C. S. Goh, H. T. Tan, K. T. Lee and N. Brosse, Biomass and Bioenergy, 2011, 35, 40254033.

37 K. Mondylaksita, J. A. Ferreira, R. Millati, W. Budhijanto, C. Niklasson and M. J. Taherzadeh, Agronomy, 2020, 10, 674.

38 D. W. K. Chin, S. Lim, Y. L. Pang, L. K. Leong and C. H. Lim, Energy Procedia, 2019, 158, $1065-1071$.

39 X. Cui, X. Zhao, J. Zeng, S. K. Loh, Y. M. Choo and D. Liu, Bioresour. Technol., 2014, 166, $584-591$.

40 R. J. Wooley and V. Putsche, Development of an ASPEN PLUS Physical Property Database for Biofuel Components, NREL Tech. Rep. NREL/TP-425-20685, 1996.

41 A. Dutta, M. Talmadge, J. Hensley, M. Worley, D. Dudgeon, D. Barton, P. Groenendijk, D. Ferrari, B. Stears, E. M. Searcy, C. T. Wright and J. R. Hess, Process design and economics for conversion of lignocellulosic biomass to ethanol, NREL Tech. Rep. NREL/TP-5100-51400, 2011. 
42 J. Kautto, M. J. Realff and A. J. Ragauskas, Biomass Convers. Biorefinery, 2013, 3, 199212.

43 US Pat., US5788812, 1998.

$44 \quad$ NL Pat., NL2011164C2, 2013.

45 C. Arato, E. K. Pye and G. Gjennestad, Appl. Biochem. Biotechnol. - Part A Enzym. Eng. Biotechnol., 2005, 123, 871-882.

$46 \mathrm{H}$. Li, J. Swithenbank and V. Sharifi, EPSRC Thermal Management of Industrial Processes: A Review of Drying Technologies, SUWIC, Sheffield University, Sheffield, UK, 2010.

47 G. Towler and R. K. Sinnott, Chemical Engineering Design - Principles, Practice and Economics of Plant and Process Design (2nd Edition), Butterworth-Heinemann, Oxford, UK, 2013.

48 B. C. Vidal, B. S. Dien, K. C. Ting and V. Singh, Appl. Biochem. Biotechnol., 2011, 164, $1405-1421$.

49 C. Mayer-Laigle, N. Blanc, R. K. Rajaonarivony and X. Rouau, Bioengineering, 2018, 5, 41.

50 H. Li, Q. Chen, X. Zhang, K. N. Finney, V. N. Sharifi and J. Swithenbank, Appl. Therm. Eng., 2012, 35, 71-80.

51 W. D. Seider, S. Junior D and D. R. Lewin, Product and process design principles: synthesis, analysis and evaluation, John Wiley \& Sons, New York, USA, 2009.

52 C. Vila, V. Santos and J. C. Parajó, Ind. Eng. Chem. Res., 2003, 42, 349-356.

53 E. Felissia Fernando, E. María Vallejos and M. C. Area, Cellul. Chem. Technol., 2010, 44, 
$311-318$.

54 R. Rivero and M. Garfias, Energy, 2006, 31, 3310-3326.

55 J. Szargut, Exergy method: technical and ecological applications, WIT Press, Southampton, UK, 2005, vol. 18.

56 J. Szargut, Appl. Energy, 1989, 32, 269-286.

57 J. Ahrendts, Energy, 1980, 5, 667-677.

58 R. C. Reid, J. M. Prausnitz and B. E. Poling, The properties of gases and liquids, McGraw Hill, New York, USA, 1987.

59 J. H. Shieh and L. T. Fan, Energy Sources, 1982, 6, 1-46.

60 NEA, NEA | Waste Statistics and Overall Recycling, https://www.nea.gov.sg/ourservices/waste-management/waste-statistics-and-overall-recycling, (accessed 4 May 2020).

61 L. Ye, M. S. Bin Hudari, X. Zhou, D. Zhang, Z. Li and J. C. Wu, Appl. Microbiol. Biotechnol., $2013,97,4831-4838$.

62 F. Harahap, S. Leduc, S. Mesfun, D. Khatiwada, F. Kraxner and S. Silveira, Energies, 2019, $12,420$.

63 From trash to treasure: Industrial chemicals from agricultural waste - A*STAR Research, https://research.a-star.edu.sg/articles/features/from-trash-to-treasure-industrialchemicals-from-agricultural-waste/, (accessed 18 June 2020).

64 NEA | Food Waste Valorisation, https://www.nea.gov.sg/our-services/wastemanagement/3r-programmes-and-resources/food-waste-management/food-wastevalorisation, (accessed 30 August 2021). 
65 S. Boh, Turning soya bean waste into packaging, Singapore News \& Top Stories - The Straits Times, https://www.straitstimes.com/singapore/turning-soya-bean-wasteinto-packaging, (accessed 12 June 2020).

66 S. Li, D. Zhu, K. Li, Y. Yang, Z. Lei and Z. Zhang, ISRN Ind. Eng., 2013, 2013, 423590.

67 S. I. Mussatto, J. Sci. Food Agric., 2014, 94, 1264-1275.

68 J. C. del Río, P. Prinsen and A. Gutiérrez, J. Cereal Sci., 2013, 58, 248-254.

69 A. L. McCarthy, Y. C. O'Callaghan, C. O. Piggott, R. J. FitzGerald and N. M. O’Brien, Proc. Nutr. Soc., 2013, 72, 117-125.

70 S. H. Ho, Y. D. Wong and V. W. C. Chang, Resour. Conserv. Recycl., 2014, 91, 117-124.

71 UglyGood | Circular Economy - ZeroWaste Initiative | Singapore, https://www.uglygood.com.sg/, (accessed 30 August 2021).

72 A. A. Lapkin, P. K. Heer, P. M. Jacob, M. Hutchby, W. Cunningham, S. D. Bull and M. G. Davidson, Faraday Discuss., 2017, 202, 483-496.

73 N. Yan, Beyond the boundaries of biomass production, International Innovation, 2014, 89-91.

74 X. Chen, H. Yang and N. Yan, Chem. - A Eur. J., 2016, 22, 13402-13421.

75 Product - Soynergy, https://www.soynergy.com/product/, (accessed 30 August 2021).

76 Oh soy: Singapore team eyes commercialisation after turning okara into DHA-rich products to aid brain health, https://www.nutraingredientsasia.com/Article/2020/09/17/Oh-soy-Singapore-team-eyes-commercialisation-afterturning-okara-into-DHA-rich-products-to-aid-brain-health\#, (accessed 30 August 2021). 
77 A1 Environment - Making the world greener, one day at a time., https://a1environment.com.sg/, (accessed 31 August 2021).

78 S. G. Wettstein, D. Martin Alonso, E. I. Gürbüz and J. A. Dumesic, Curr. Opin. Chem. Eng., 2012, 1, 218-224.

79 F. H. Isikgor and C. R. Becer, Polym. Chem., 2015, 6, 4497-4559.

80 N. Abdullah and F. Sulaiman, Biomass Now - Sustain. Growth Use, 2013, 75-100.

81 Overview of Industry 2019 - PALMOILIS, http://palmoilis.mpob.gov.my/V4/overviewof-industry-2019/, (accessed 29 September 2021).

82 GAPKI, The Reflection on Palm Oil Industry in 2019 and Prospect for 2020 | Indonesian Palm Oil Association (GAPKI IPOA), https://gapki.id/en/news/18425/the-reflection-onpalm-oil-industry-in-2019-and-prospect-for-2020, (accessed 16 June 2020).

83 M. Junginger, J. Koppejan and C. S. Goh, Sustain. Sci., 2019, 15, 1455-1459.

84 N. James Rubinsin, W. R. W. Daud, S. K. Kamarudin, M. S. Masdar, M. I. Rosli, S. Samsatli, J. F. Tapia, W. A. Wan Ab Karim Ghani and K. L. Lim, Food Bioprod. Process., 2020, 119, 179-194.

85 W. P. Q. Ng, H. L. Lam, F. Y. Ng, M. Kamal and J. H. E. Lim, J. Clean. Prod., 2012, 34, 5765.

86 M. F. Awalludin, O. Sulaiman, R. Hashim and W. N. A. W. Nadhari, Renew. Sustain. Energy Rev., 2015, 50, 1469-1484.

87 M. A. A. Farid, M. A. Hassan, M. R. Othman, Y. Shirai and H. Ariffin, in Lignocellulose for Future Bioeconomy, 2019, pp. 207-242.

88 F. B. Ahmad, Z. Zhang, W. O. S. Doherty and I. M. O'Hara, Biofuels, Bioprod. Biorefining, 
2016, 10, 378-392.

89 F. B. Ahmad, Z. Zhang, W. O. S. Doherty, V. S. J. Te'o and I. M. O'Hara, Fuel, 2017, 194, $180-187$.

90 M. S. Sajab, S. Harun, S. I. Zubairi, A. Mohd Tajuddin, J. Md Jahim, M. T. Mohd Nor, M. Markom, M. A. Abdullah and N. Hashim, Int. J. Eng. Technol., 2019, 8, 266-274.

91 P. L. Tang, P. M. Abdul, N. S. Engliman and O. Hassan, Cellulose, 2018, 25, 1-18.

92 S. N. Rosli, S. Harun, J. . Jahim and R. Othaman, Malaysian J. Anal. Sci., 2017, 21, 188196.

93 S. Kim and C. H. Kim, Renew. Energy, 2013, 54, 150-155.

94 J. Dewulf, H. Van Langenhove, B. Muys, S. Bruers, B. R. Bakshi, G. F. Grubb, D. M. Paulus and E. Sciubba, Environ. Sci. Technol., 2008, 42, 2221-2232. 
Integration of biowaste into chemical reaction networks. A case study of the waste landscape around Singapore

\author{
Adarsh Arun, $^{a, c}$ Jana M. Weber, ${ }^{a, b}$ Zhen Guo $^{b, c}$ and Alexei A. Lapkin ${ }^{a, b, c^{*}}$ \\ ${ }^{a}$ Department of Chemical Engineering and Biotechnology, University of Cambridge, Philippa \\ Fawcett Drive, Cambridge CB3 OAS, UK \\ ${ }^{b}$ Chemical Data Intelligence (CDI) Pte Ltd, Robinson Road, \#02-00, 068898 Singapore \\ ${ }^{c}$ Cambridge Centre for Advanced Research and Education in Singapore, CARES Ltd. 1 CREATE \\ Way, CREATE Tower \#05-05, 138602 Singapore
}

\title{
SUPPORTING INFORMATION
}

\section{List of Figures}

Figure S1. A simplified illustration of a pretreatment network and its integration with a reaction network based on a case study of Singapore (as well as Malaysia and Indonesia) 


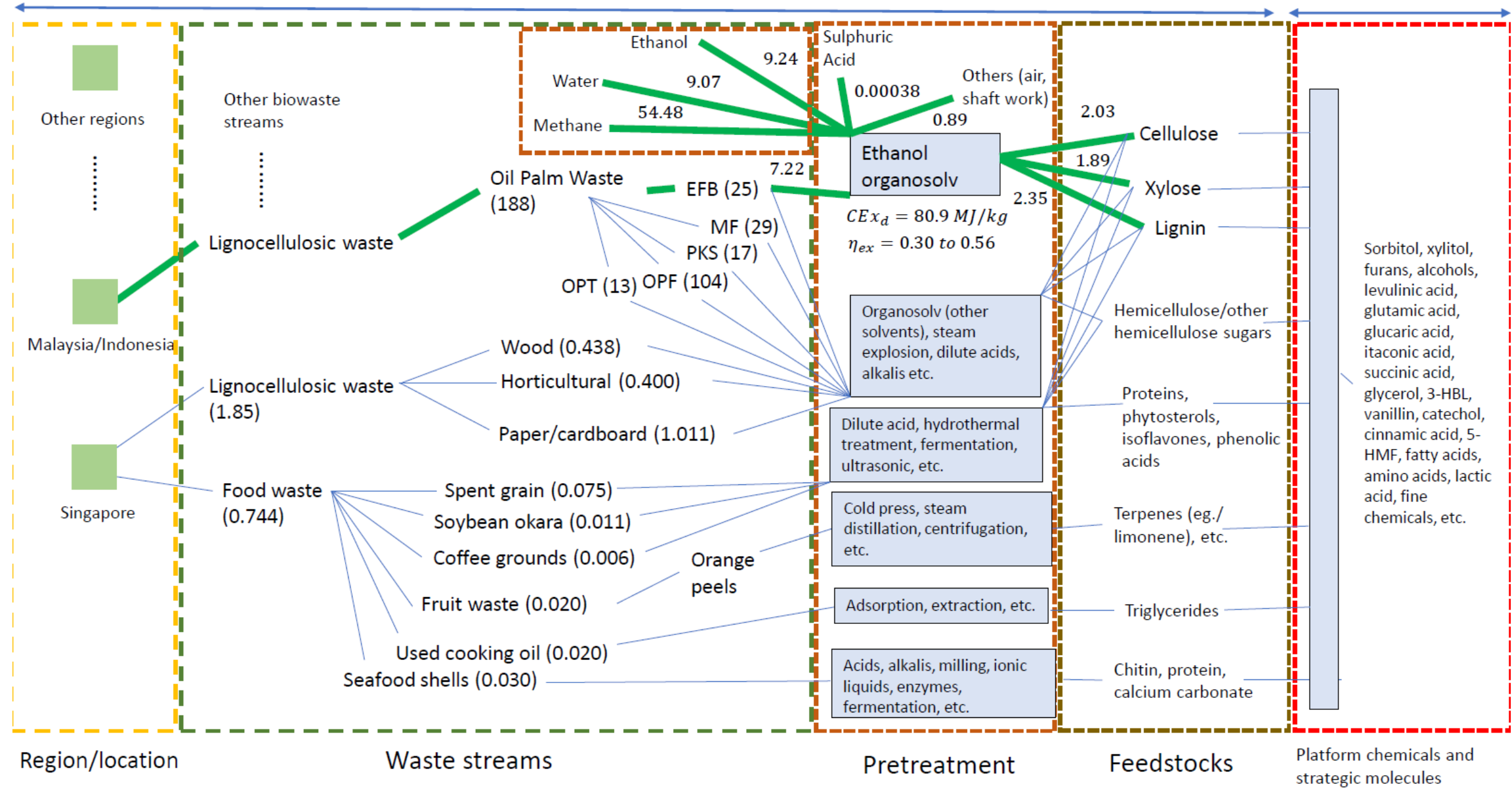

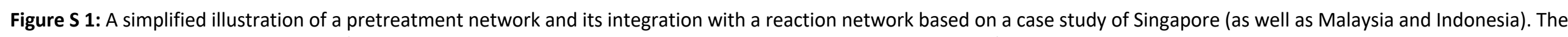

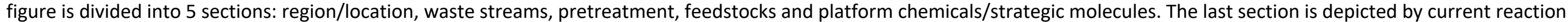
networks, and has not been expanded in detail here. A product molecule section can still be added, but has been excluded here for simplicity. The chosen waste stream, and

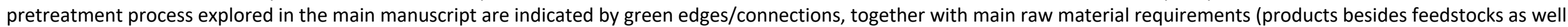

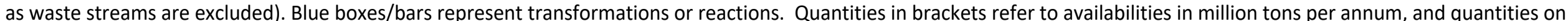

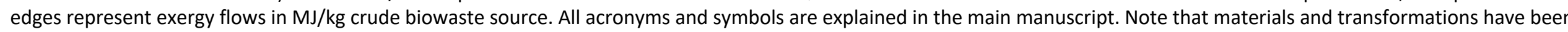

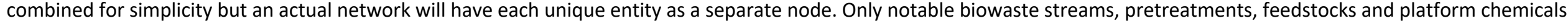
outlined in the paper have been indicated here; in reality, there are likely to be more. 